\title{
Viral tolerance in Aedes aegypti relies on the negative cooperativity between Toll5A and the cytokine ligand Spz1C
}

\author{
Yoann Saucereau ${ }^{1}$, Tom H. Wilson ${ }^{1}$, Martin C. Moncrieffe ${ }^{1}$, Steven W. Hardwick ${ }^{1}$, Dimitri Y. Chirgadze ${ }^{1}$, Maria $^{2}$ \\ Jose Marcaida $^{2}$, Nick Gay ${ }^{1}$, Monique Gangloff ${ }^{*}$ \\ ${ }^{1}$ Department of Biochemistry; University of Cambridge, 80 Tennis Court Road, Cambridge CB2 1GA; United \\ Kingdom. ${ }^{2}$ Institute of Bioengineering, School of Life Sciences, Ecole Polytechnique Fédérale de Lausanne; \\ Lausanne, Switzerland. \\ ${ }^{*}$ Corresponding Author: Dr Monique Gangloff. Department of Biochemistry, University of Cambridge. 80 Tennis \\ Court Road, Cambridge CB2 1GA. United Kingdom. Correspondence: mg308@cam.ac.uk.
}

\begin{abstract}
A. aegypti has evolved to become an efficient vector of Dengue viruses among other arboviruses despite Toll-regulated infection levels. Interestingly, both Toll and its ligand Spätzle (Spz) have undergone gene duplication in $A$. aegypti raising the possibility of neofunctionalization and mutualism to develop between arboviruses and mosquitoes. Here we present cryo-EM structures and biophysical characterisation of low affinity Toll5A-Spz1C complexes that display transient but specific interactions. Binding of the first ligand alters receptor-receptor interactions and promotes asymmetric contacts in the vicinity of the Z-loop in Toll5A. This conformation then restricts binding of a second ligand, while bridging the $\mathrm{C}$ termini that promote signalling. In contrast, increased receptor concentrations promote inactivating head-to-head receptor assemblies. We also found that Spz1C differs from orthologous and paralogous cytokines in their transcriptional responses upon A. aegypti Aag2 cell stimulation. Interestingly, Spz1C uniquely controls genes involved in innate immunity, lipid metabolism and tissue regeneration. Given the remarkable DENV-induced expression patterns of these proteins, our data rationalises how Spz1C upregulation might promote innate immunity in the midgut, and Toll5A upregulation, viral tolerance in the salivary glands.
\end{abstract}

\section{KEYWORDS}

Toll receptor; Spätzle cytokine; Aedes aegypti; immunity; Dengue; vectorial capacity; cryoEM; RNAseq 


\section{INTRODUCTION}

Insect Toll receptors perform critical functions in both embryogenesis and innate immunity. They are part of an ancient defence system that also includes the immunodeficiency (IMD) pathway and are conserved in vertebrates as the Toll-like receptors. Tolls and TLRs have a modular structure with an ectodomain made up of leucine rich repeats (LRRs) and associated capping structures, a single transmembrane helix and a cytosolic Toll/Interleukin 1 receptor (TIR) domains (Gay et al., 2014). Most studies of innate immune function in insects have focussed on the fruit fly Drosophila melanogaster (Hoffmann, 2003). The Drosophila genome encodes 9 Toll receptors that have diverse roles in development and other areas of cellular regulation as well as in immunity. Immune function is mediated mainly by the Toll receptor 1 (Toll1), while Toll6 and Toll7 are expressed in the nervous system and have equivalent functions to vertebrate neurotrophin receptors (McIlroy et al., 2013).

Toll receptors are activated by a complementary family of six cytokine-like molecules called Spätzle (Spz) (Parker et al., 2001). Spz proteins are secreted as larger dimeric precursors consisting of a natively unstructured pro-domain, which is proteolytically cleaved upon activation and a C-terminal cystine-knot fold similar to that found in human neurotrophins, such as nerve growth factor (Arnot et al., 2010). In the case of Spz1, Lys-type peptidoglycan from Gram-positive bacteria is detected by recognition proteins PGRP-SA, -SD, and GNBP1 and these complexes activate a cascade of serine proteases (Wang et al., 2008). The terminal proteinase, Spätzle processing enzyme (SPE), has trypsin-like specificity and cleaves the Spz precursor specifically at the junction between the pro-domain and cystine-knot which remain associated by non-covalent interactions (Jang et al., 2006). Spz2 (also called neurotrophin-1, NT1) and Spz5 (NT2) are cleaved during secretion by furin-like proteases (Foldi et al., 2017) and, in the case of Spz2, a truncated prodomain and the cystine knot remain associated noncovalently. By contrast, Spz5 is secreted as a mature form without the prodomain. Growing evidence suggest promiscuity in ligand binding, with Toll1 and Toll7 recognising Spz1, Spz2 and Spz5 as well as vesicular stomatitis virus (VSV) virions (Chowdhury et al., 2019; Nakamoto et al., 2012; Nonaka et al., 2018; Shelly et al., 2009), while Toll6 senses Spz2 and Spz5 (Foldi et al., 2017).

Mosquitoes and fruit flies are both dipterans but they diverged in evolution about 260 million years ago (Chen et al., 2015; Nene et al., 2007). Comparative genomic analysis of Aedes aegypti, Anopheles gambiae and Drosophila melanogaster reveals that most genes involved in innate immunity are conserved in the mosquito including the Toll and Spätzle families (Christophides et al., 2002). Nevertheless, the Toll family has undergone significant diversification with the loss of orthologs in mosquitoes (no Toll2 or Toll3 in A. aegypti, for example) and species-specific expansion of two more (Toll10 and Toll11). The underlying driving force of gene duplication is likely interconnected with the mosquito's change to a hematophagous diet and the evolutionary arms-race between pathogens and insects. In Drosophila Toll1 mediates most immune functions while in Aedes two gene reduplications have occurred to produce an orthologous group of four closely related receptors Toll1A, Toll1B, Toll5A and Toll5B. The phylogeny does not provide unequivocal evidence as to which of these receptors function in immunity or if they have acquired new functions upon diversification.

Although there is a clear evolutionary relationship between insect Tolls and vertebrate TLRs the latter appear to have arisen from the atypical insect Toll9 and adapted to directly recognise a diverse range of pathogen associated molecular patterns (PAMPs) such a bacterial lipopolysaccharide (Gay and Gangloff, 2007). Thus, vertebrate TLRs are bona fide pattern 
recognition receptors but insect Tolls are activated by endogenous cytokines or growth factors, with the exception of VSV recognition. Another distinction between Toll and TLRs is the kinetics of receptor activation. TLRs display positive cooperativity being activated over a narrow range of ligand concentrations (Gay et al., 2006). By contrast, the function of Toll1 in development requires a diffused gradient of active Spätzle with different threshold concentrations specifying cell fates along the embryonic dorso-ventral axis.

A third function of insect Tolls that is not shared with TLRs is cell adhesion (Keith and Gay, 1990). However, a number of other leucine rich repeat proteins including human platelet glycoprotein 1B and Drosophila Chaoptin are cell adhesion molecules (Krantz and Zipursky, 1990; Uff et al., 2002). Adhesion mediated by Toll1 may be either homo- or heterotypic although a partner for heterotypic binding has not been described and adhesion does not activate signal transduction. In the embryo Toll1 is transiently expressed in a specific subset of muscle fibres and may mediate formation of neuromuscular junctions together with another nonreceptor LRR protein Connectin (Inaki et al., 2010; Nose et al., 1992; Rose et al., 1997).

Structural studies have provided insight into the molecular mechanism by which PAMPS activate the TLRs (Kang and Lee, 2011). A common feature is stimulus-induced dimerization of the receptor ectodomains or alternatively conformational rearrangement of a preformed inactive dimer. For example, double stranded RNA crosslinks two TLR3 ectodomains causing the juxtamembrane regions to move into close proximity and promoting dimerization of the TIR domains in the cytosol (Liu et al., 2008). By contrast, TLR8 is expressed as pre-formed dimer and binding of small drug molecules or single stranded RNA induces a conformational rearrangement of the dimer interface that causes the two ectodomains to tilt together and, like TLR3, moves the juxtamembrane C-termini into close proximity (Tanji et al., 2013). It is likely that activation of insect Toll receptors by Spätzle ligands involves similar conformational changes. In that regard biochemical evidence suggests that the active complex is a 2:2 heterotetramer with two molecules of receptor and two molecules of Spätzle-C106 (Weber et al., 2005). However, to date the only crystal structures of the Toll-C106 complex reveal a 1:1 complex with a binding mode that is reminiscent of mammalian neurotrophins (Lewis et al., 2013; Parthier et al., 2014). The covalent cystine-knot dimer forms asymmetric contacts at the concave side of the N-terminal cap and within the first ten LRRs. In contrast to TLRs, Spätzle does not induce dimerization of the receptor in the crystal structure possibly because negative cooperativity requires that the active signalling complex is unstable.

Drosophila has served as a model system for insects but adaptation to blood-borne pathogens by mosquitoes seems to have driven the evolution of their innate immune system. The Toll pathway has been involved in resistance against Dengue virus (Ramirez and Dimopoulos, 2010; $\mathrm{Xi}$ et al., 2008). However, differential expression of duplicated Toll5A and Spz1C suggests that this pathway is regulated in a tissue-specific manner (Luplertlop et al., 2011; Wang et al., 2019). Dengue-induced upregulation could be related to the involvement of this pathway in viral tolerance. Here we propose that Dengue viruses exploit a mechanism, which helps the mosquito distinguish between acute and persistent infections to achieve immune quiescence. We use purified proteins to further characterise Toll5A-Spz1C interactions and the impact of their relative concentrations. Single particle cryo-EM reveals that the receptor is crosslinked in an asymmetric complex, in which C-terminal regions are brought into proximity upon Spz1C binding, which is a structural requirement for signal transduction. Along with the functional characterisation of Spz1C-induced A. aegypti Aag2 cell signalling, our study sheds new light on the effect of duplication and shows the importance of revisiting Toll signalling in hematophagous insects that impact human health. 


\section{RESULTS}

\section{CryoEM of Toll5A-Spz1C single particles.}

To gain mechanistic insight into the activation of Toll5A by ligand Spz1C, we carried out single particle cryo-EM to determine the structure of the stable complexes formed by the receptor ectodomain and the activated ligand. Recombinant Toll5A ectodomain was mixed with a 3 -fold molar excess of Spz1C and further purified by size exclusion chromatography immediately prior to grid preparation as described in Methods. We then visualised 3 oligomeric states of the receptor at near atomic resolutions, suggesting that Toll5A is highly dynamic in the presence of Spz1C. The resolution of the original maps was extended by density modification with ResolveCryoEM (Terwilliger et al., 2020). Homodimers of Toll5A at $3.41 \AA$ maximum resolution had 85,810 particles, 2:1 heterodimers of Toll5A bound to Spz1C at $4.23 \AA$ had 40,153 particles, and a 3:1 heterotrimer at 3.74 $\AA$ had 42,866 particles (Fig. 1 and S1).

A

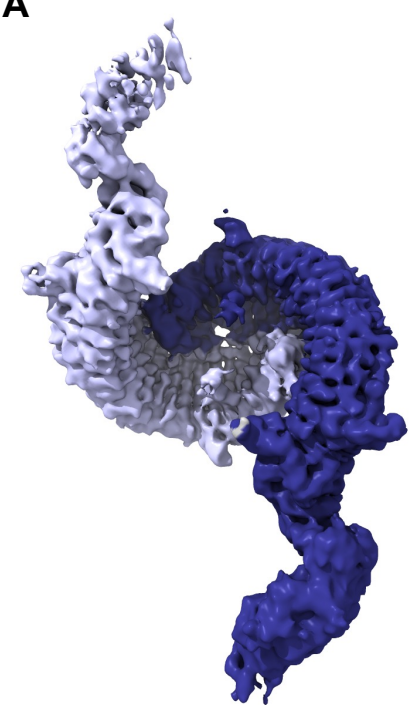

D

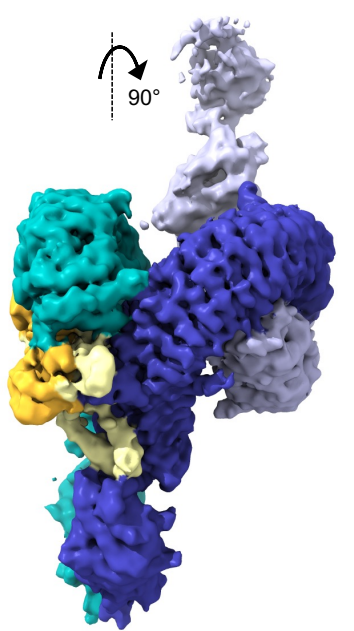

B

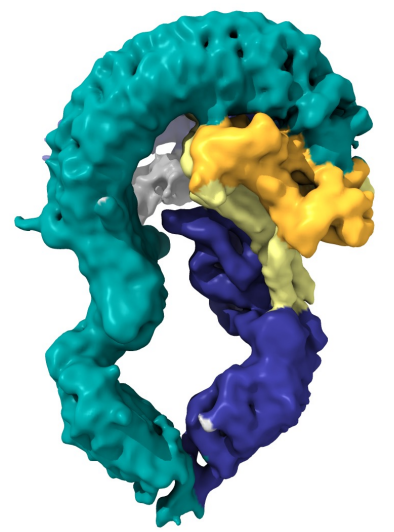

E

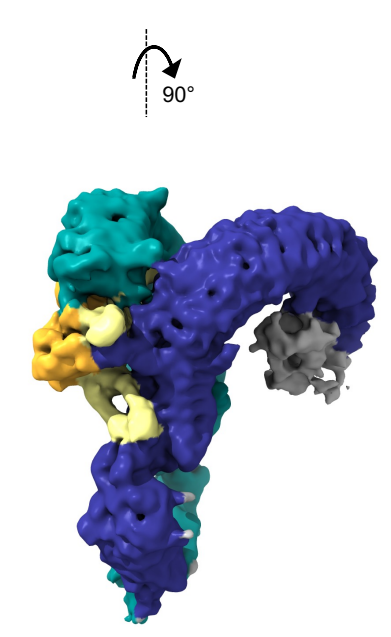

C

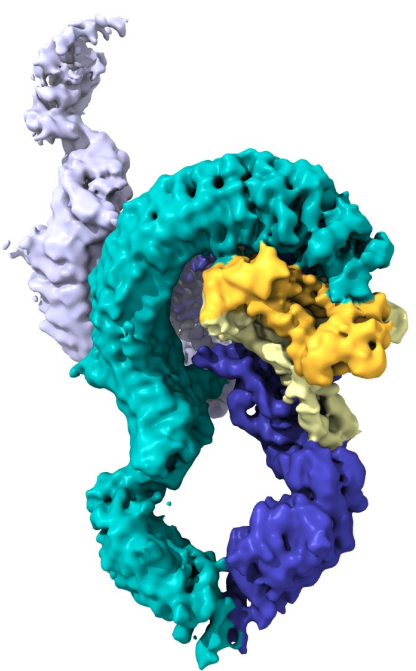

$\mathbf{F}$

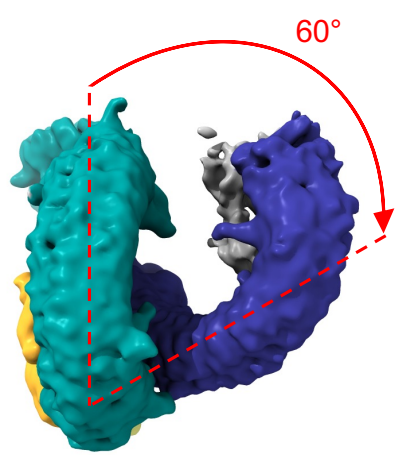

Toll5A (ECD)

chain $A$

chain B chain C

\section{Spz1C (CKD)}

chain $E$

$2^{\text {nd }}$ ligand

Figure 1: Cryo-EM reveals three particles with variable stoichiometries that reflect the dynamic nature of the system. 2:0 ligand-free Toll5A homodimer (A), 2:1 single-ligated heterodimer (B), and (C) 3:1 single-ligated heterotrimer. Density is colour-coded according to protein content. A different orientation rotated by $90^{\circ}$ along a vertical axis defined by the dimerization axis is shown for the 3:1 (D) and the 2:1 complexes (E). The latter is also shown with a top view to emphasize the deviation of chain B by $60^{\circ}$ from the dimerization axis $(\mathbf{F})$. This configuration prevents a poorly resolved second ligand (grey density) bound at the concave side of chain B to contact the dimerization interface. 
While all three types of particles spread randomly across the grid, according to their large Euler angular distribution, they display significant variations in local resolutions, likely a consequence of their stoichiometric and conformational heterogeneity. Overall, the N-terminal LRR domains of each receptor chain achieve better resolutions than their C-terminal moieties. The latter were partially truncated upon density modification. The three Toll5A molecules observed are referred to as chain A (light blue), chain B (dark blue) and chain $\mathrm{C}$ (cyan). The Spz1C homodimer is composed of chain E (yellow) and chain F (orange), attached to Toll5A chain $\mathrm{C}$ at the concave side and to chain B at its "back" or convex side, in superimposable conformations in both the heterodimer and trimer.

Structure of Toll5A ectodomain and comparison with the prototypical Drosophila Toll1. The structure of Toll5A homodimers (chain A and chain B) was solved at the highest overall resolutions between 3.4 to $4.4 \AA$, with a head-to-head arrangement maintaining the C-terminal LRR domains far apart (Fig. 1A). The $\mathrm{C} \alpha$ atoms of Cys-783 at the C-termini of each receptor chain are separated by about $200 \AA$. Such a structural arrangement -if sterically possible when the receptor is expressed on the same cell- would ensure that Toll5A is locked in an inactivate state preventing TIR domain association and signalling. If receptors are situated on neighbouring cells, such an orientation might be relevant to cell adhesion.

The overall structure of Tol15A is comparable to DmToll1 with a conserved number of leucinerich repeats in both the $\mathrm{N}$ - and $\mathrm{C}$-terminal domains, and conserved cysteine-rich capping structures surrounding these domains. The sequences of Toll5A and DmToll1 are $30 \%$ identical and $50 \%$ similar. In particular, the extended N-terminal cap formed by two hairpins and a parallel beta-sheet, which is involved in Spz binding, is conserved in A. aegypti Toll5A but is not found in Drosophila Toll-5, also known as Tehao, which remains an orphan receptor (Luo et al., 2001).

Superimposition Toll5A and DmToll reveals that the diameter of the N-terminal LRR solenoid of Toll5A is 5-10 A greater compared to the Drosophila Toll1 receptor, with an inner diameter of about $50 \AA$ and an outer diameter of $90 \AA$. Toll5A has six glycosylation sites that restrict access to its surface. In contrast, DmToll has thirteen sites. Hence, most glycosylation sites are not conserved, except for Asn 481 on the ascending flank of LRR15 and Asn 521 on the descending flank of LRR17. Glycans restrict protein-protein contacts on the concave surface and the flanks of the receptor. In the homodimer, LRRNT1 cap residues between Thr-34 and Tyr-79 bind the concave surface in the vicinity of residues Tyr-202 (LRR4) to Asn-419 (LRR13). In particular, Tyr 56 is hydrogen bonded to Tyr 226 for each chain (Fig. 2). The buried surface area is about $1,000 \AA^{2}$. This surface is also used for Spz ligand binding suggesting a direct competition between receptor-receptor and receptor-ligand interactions. The presence of unliganded receptor in the Toll5A-Spz1C sample suggests that formation of the complex is reversible. 
A

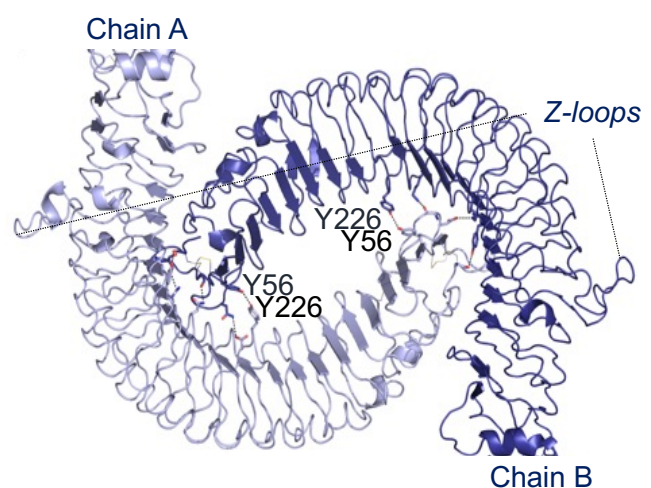

B

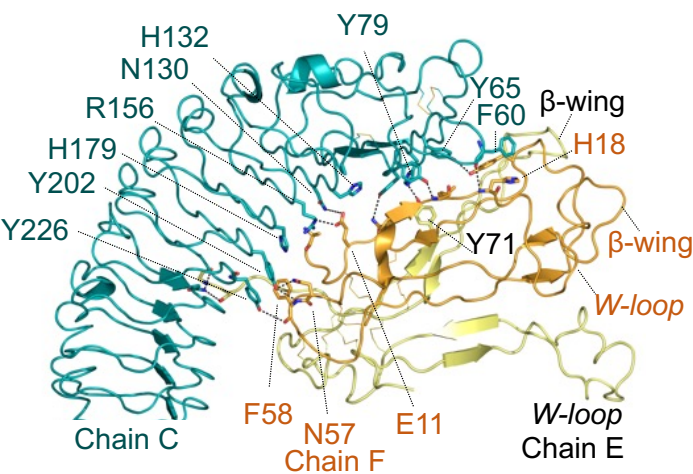

C

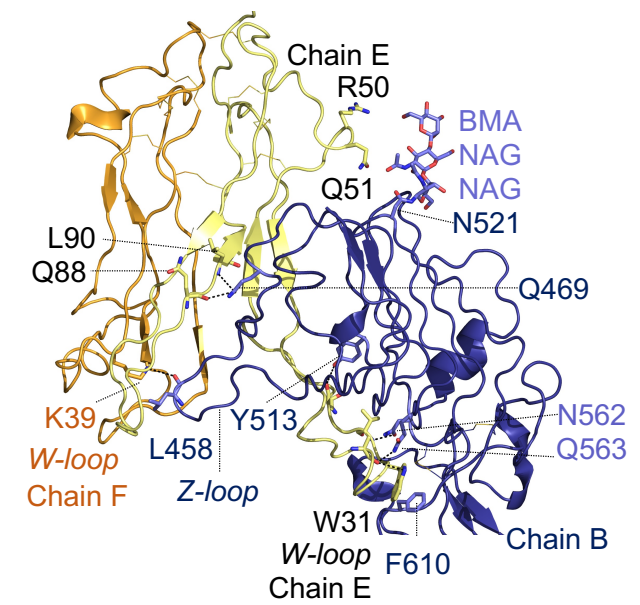

Figure 2: Receptor-receptor interactions compete with receptor-ligand interactions between Toll5A and Spz1C. N-terminal receptor-receptor interactions at LRRNT1-LRR14 with accessible LRR14 Z-loops (A) directly compete with ligand binding at the concave side of LRRNT1-LRR7 (B). Spz1C mediates extensive contacts between $\beta$-wings and the Toll5A Z-loop located between LRR14 and LRR15, with the Trp (W) loop of the distal chain E nesting between LRR domains (C). The W-loop of the proximal chain F caps the $\beta$-wings and participates in Z-loop interactions. 


\section{Spz1C binding breaks receptor symmetry and brings the receptor juxtamembrane regions into proximity.}

We observed a ligated heterodimer of Toll5A with a stoichiometry of two receptor ectodomains to one Spz1C ligand (2:1 complex) at a lower resolution between 4.2 to $8.4 \AA$. Spz1C is a covalent dimer stabilised by two intermolecular disulphide bonds instead of one in Drosophila Spz. The central disulphide bond between Cys-94 residues is conserved in DmSpz, while Spz1C has an additional intermolecular bond between the Cys-59 residues located basally in an area directly involved in binding to the N-terminal concave surface of the receptor. Cys-59 in chain $\mathrm{F}$ of Spz1C is located within hydrogen bonding distance $(3.4 \AA)$ of the hydroxyl group of Toll5A Tyr-226 in chain C LRR5 (Fig. 2B). The concave interface formed by the N-terminus up to LRR7 buries only $\sim 890 \AA^{2}$ of accessible surface area, which represents less than half that observed in the Drosophila complex (Lewis et al., 2013; Parthier et al., 2014). Nevertheless, Spz1C adopts an asymmetric binding mode, in which chain $\mathrm{F}$ contributes about $610 \AA^{2}$ and chain E, $280 \AA^{2}$ to the concave binding site (Fig. 2B). It overlaps but does not completely match the site of Drosophila Toll1 and Spz. The interactions of Spz1C chain F at the concave site involves mostly residues from the first and third $\beta$-strand of Spz1C (Gln-14 and Leu-16, and Tyr-71, respectively) with the LRRNT1 of Toll5A (chain C: Tyr-79, Tyr-65 and His-54, respectively). Hydrogen bonds occur between His-18 in the Spz1C Trp-loop and the Phe-60 main-chain carboxy group in the receptor. Spz1C Tyr-38 and Toll5A Tyr-56 interact with side chain-mediated contacts (Fig. 2B). There is a salt bridge between Arg-156 in Toll5A LRR2 and Glu-11 in Spz1C chain F. The same residue in chain E is solvent-exposed and not well resolved in density. Glycans linked to Asn-521 on LRR17 restrict Spz1C spatially in the vicinity of Arg50 and Gln-51 in chain E (Fig. 2C).

The overall structure of Spz1C is very similar to DmSpz, if the flexible Trp-loops between residues His-18 and Gln-40, and the $\beta$-wings between residues Tyr-71 and Val-89, are omitted. Indeed, the R.M.S.D of superimposed Cys-knot domains is about $2.2 \AA$ over $53 \mathrm{C} \alpha$ atoms in the absence of these flexible regions (Arnot et al., 2010; Hoffmann et al., 2008; Lewis et al., 2013; Parthier et al., 2014). Interestingly, in the mosquito Toll5A-Spz1C complex, these loops define asymmetric contacts at the dimerization interface with the "back" of chain B (Fig. 2C). Chain E of Spz1C binds extensively to the dimerization interface with over 1,300 $\AA^{2}$ of its accessible surface area, while chain F contributes only $180 \AA^{2}$, confined to a loop that protrudes from the convex side of LRR14. Remarkably, the integrity of the LRR14 loop seems to determine the dynamic interactions between Toll5A and Spz1C, while its cleavage stabilises the complex (Fig. S2). This property is reminiscent of the Z-loop of nucleic-sensing TLRs (Ewald et al., 2011, 2008; Park et al., 2008; Tanji et al., 2013). We will therefore refer to it as the Z-loop with conserved Asn and Asp residues suitable for Asparagine endopeptidase (AEP) processing (Maschalidi et al., 2012; Sepulveda et al., 2009), while noting the absence of a cathepsin site in Toll5A.

In the unbound state the $\beta$-wings of DmSpz are displaced from the Cys-knot framework by $90^{\circ}$ (Hoffmann et al., 2008). By contrast in our structure the $\beta$-wings adopt a different conformation that holds the Z-loop in a pincer like arrangement (Fig. S2A). As most side chains are poorly resolved in the cryoEM data we generated a complete structure by side chain modelling, which is suitable for surface analysis (Fig. S3). This analysis suggests that electrostatic charge distribution and shape complementarity allow such a receptor-ligand coupling and conformational selection. The dimerization interface of $1,480 \AA^{2}$ is one and a half times the area of the concave binding surface, suggesting a higher affinity binding compared to the concave interface. The absence of particles with a stoichiometry of $1: 1$ may indicate a sequential mechanism of assembly achieved upon saturation. 
Interestingly, the $\mathrm{N}$-terminal region of Toll5A chain $\mathrm{B}$ deviates by an angle of $\sim 60^{\circ}$, compared to the axis traversing chain $\mathrm{C}$ from $\mathrm{N}$ - to $\mathrm{C}$-terminus (Fig. 1). There is evidence of extra density in the original 2:1 heterodimer map that matches the dimensions of a Cys-knot domain without its loops. However, there is no possible contact at the dimer interface for the second ligand in the current configuration. Hence, the asymmetric disposition of the receptor chains is the molecular basis of negative cooperativity in the system, where binding of the first ligand makes binding of a second molecule energetically unfavourable.

\section{The receptor competes with ligand binding.}

A third particle was observed with a stoichiometry of 3 receptors and 1 ligand (Fig. 1). It is a hybrid of the homodimer (Toll5A chains A and B) and the 2:1 Toll5A-Spz1C heterodimer (Toll5A chains B and C) leading to a trimer of A, B and C chains, with Spz1C bound to the back of chain $\mathrm{B}$ and the concave side of chain $\mathrm{C}$ without any further contacts with chain $\mathrm{A}$. Some minor differences are observed in main-chain and side-chains positions, which might be due to flexibility in both receptor and ligand molecules and the intermediate resolution of the heterotrimer map at $3.7-4.7 \AA$, compared to the homo- and heterodimer. While binding of a first Spz1C ligand shifts the receptor to adopt an asymmetric dimer configuration, the second binding site remains predominantly associated to another receptor chain.

\section{Receptor specificity is achieved with low ligand binding affinity}

The interactions between Spz1C, and the ectodomain of Toll5A were characterised using a range of biophysical techniques. We used surface-plasmon resonance to measure the kinetics of association and dissociation between mosquito and Drosophila Toll and Spz proteins (Fig. 3A and S4) and found that Toll5A only binds Spz1C. Surprisingly, A. aegypti Spz1A did not bind Toll1A, despite being the closest structural homologues of DmToll1 and DmSpz1 in the mosquito. Spz1A did not bind Toll5A, and neither did DmSpz1. Furthermore, Spz1C did not bind Toll1A or DmToll1, suggesting receptor-ligand specificity. By contrast, Toll5A and Spz1C interact with a $K_{D}$ value of $\sim 2 \mu \mathrm{M}$ whereas Drosophila Toll binds Spz with a much higher affinity of 30-80 nM, consistent with previous studies (Weber et al., 2003). Hence, the Toll5A-Spz1C complex is species- and paralogue specific despite being of low affinity.

\section{Ligand binding triggers a conformational change within Toll5A dimers in solution}

We then used SEC-MALS experiments in the presence and absence of Spz1C to characterise the stoichiometry of the receptor and its complex. This technique revealed a concentrationdependent shift in the stoichiometry of the receptor, from a monomer to a homodimer in the absence of ligand when the concentration was increased from 20 to $50 \mu \mathrm{M}$ prior to sizeexclusion chromatography (Fig. 3). Complexes were prepared in the presence of a three molar excess ligand and gel-filtered before analysis. In the presence of $20 \mu \mathrm{M}$ Toll5A saturated with Spz1C, a complex formed that was polydisperse but at $50 \mu \mathrm{M}$ Toll5A saturated with Spz1C, the mixture appeared monodisperse with a mass corresponding to $206 \mathrm{kDa}$. SEC-MALS indicates a mass of $175 \mathrm{kDa}$ for the unbound receptor dimer so the $206 \mathrm{kDa}$ form is consistent with a 2:1 complex of Toll5A and a disulphide linked Spz1C dimer (26 kDa).

We then explored this 2:1 complex further using SEC-SAXS at $50 \mu \mathrm{M}$ prepared as above and compared it to the receptor homodimer at the same concentration and in the same buffer. SAXS allows rapid assessment of structural changes in response to ligand binding and can quantitatively characterize flexible molecules. The Guinier plot demonstrates the aggregationfree state of the receptor and its complex (Fig. S5). As one of the few structural techniques amenable to dynamical systems, SAXS analysis suggests that the 2:1 complex is less flexible 
than the homodimer, despite its slightly larger dimensions (Table S2). Hence, the receptor likely undergoes conformational changes upon ligand binding.

A

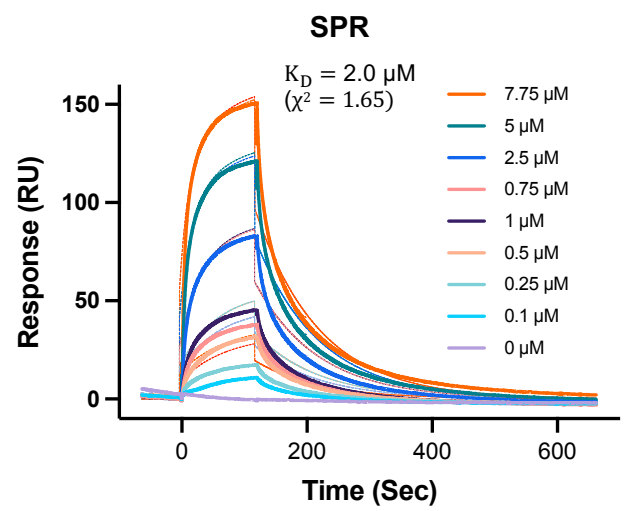

C

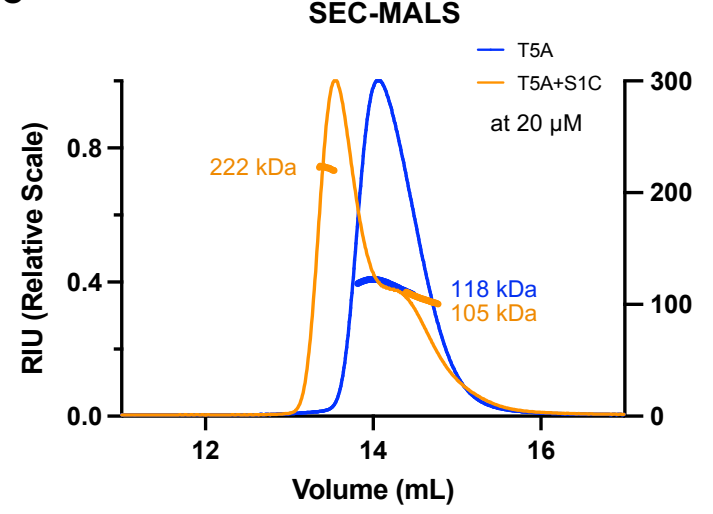

B

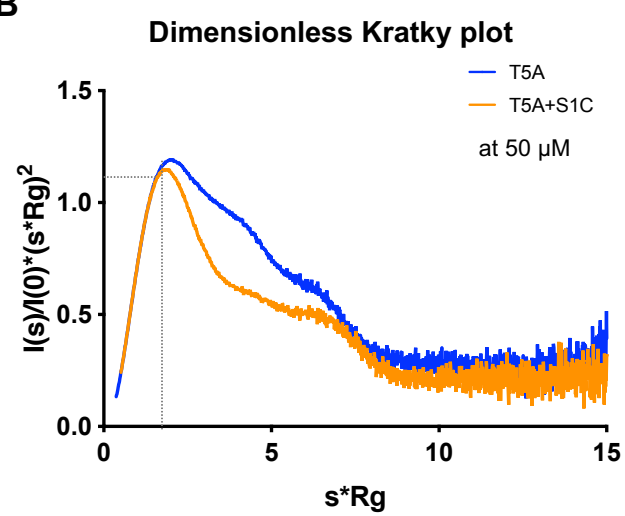

D

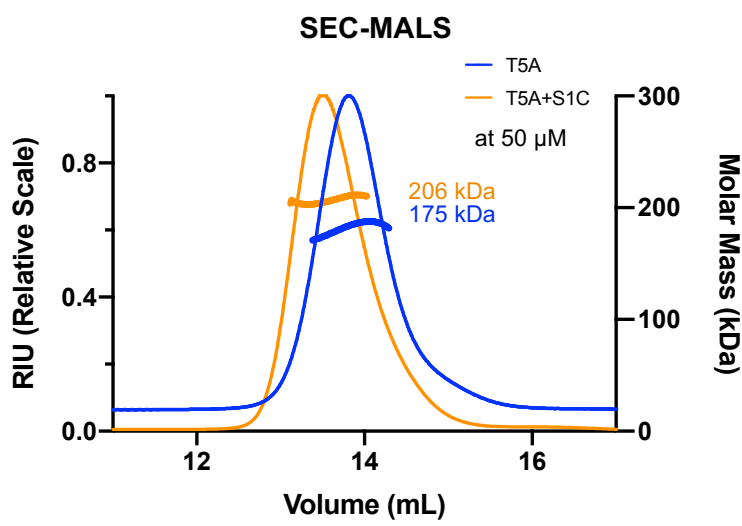

Figure 3: Spz1C low affinity binding to Toll5A homodimer decreases protein complex flexibility. SPR binding analysis (A). Sensorgrams of Toll5A (acronym, T5A) run over a range of concentrations $(0.1-7.5 \mu \mathrm{M})$ on an amine coupled Spz1C-chip (acronym, S1C). SEC-SAXS dimensionless Kratky plot analysis at $50 \mu \mathrm{M}(\mathbf{B})$. SEC-MALS analysis at $20 \mu \mathrm{M}(\mathbf{C})$ and $50 \mu \mathrm{M}$ (D) of Toll5A on its own (blue) and in complex with Spz1C (orange). Both MALS and SAXS were carried out upon loading $50 \mu \mathrm{l}$ samples at the given concentrations onto a Superose 6 size-exclusion chromatography column (GE Healthcare) in $50 \mathrm{mM}$ Tris pH 7.5, $50 \mathrm{mM} \mathrm{NaCl}$.

\section{Toll5A-Spz1C complexes undergo dynamic exchange}

The linearity of the Guinier plot (Fig. S5) does not ensure the ideality of the sample, hence further direct methods were used in solution and under native conditions. We used Analytical Ultracentrifugation (AUC) to determine relative concentrations, sedimentation coefficients, molecular weights and shape (frictional ratio) of Toll5A and Toll5A-Spz1C complexes (Fig. S6). These experiments reveal that Toll5A ectodomain alone is in equilibrium between monomers $(\leq 3 \mu \mathrm{M})$ and dimers that prevail at concentrations $\geq 30 \mu \mathrm{M}$ (Fig. 4A). The concentration-dependent stoichiometry differs from SEC-MALS, for which monomeric receptor was observed at $20 \mu \mathrm{M}$, most likely as a consequence of sample dilution or the effect of the matrix on protein-protein interactions during the size-exclusion chromatography step that precedes MALS.

The shape of the AUC curves indicates that receptor-receptor interactions undergo slow exchanges, defined by discrete peaks at $5.6 \mathrm{~S}$, and $7.3 \mathrm{~S}$, respectively. In contrast, the presence 
of Spz1C at equimolar concentration causes the formation of Toll5A-Spz1C complexes with sedimentation coefficients ranging between 5.5 and 8.6S (Fig. 4B). Toll5A forms heterogenous complexes with its ligand, which may include a $1: 1$ complex at $6.7 \mathrm{~S}$, as well $7.3 \mathrm{~S}$ (homodimers) and $7.8 \mathrm{~S}$ species (2:1 heterodimers) in different conformational states. However, in the presence of excess Spz1C, better resolved molecular species sediment as two distinct populations of $6.7 \mathrm{~S}$ and $8.5 \mathrm{~S}$. These complexes are reminiscent of the $1: 1$ and 2:2 complexes formed by DmToll and Spz in similar experimental conditions (Parthier et al., 2014; Weber et al., 2005).

A

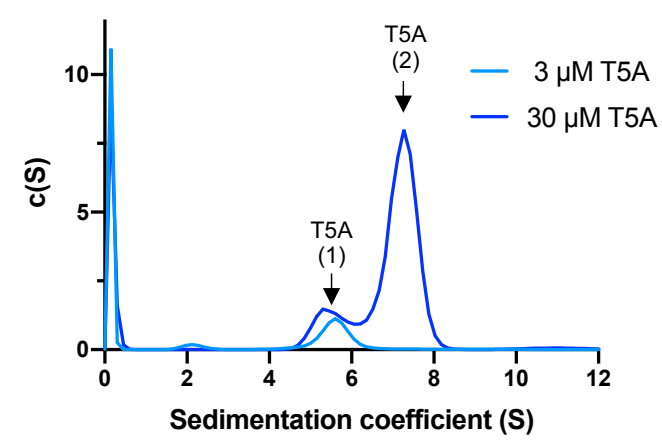

C

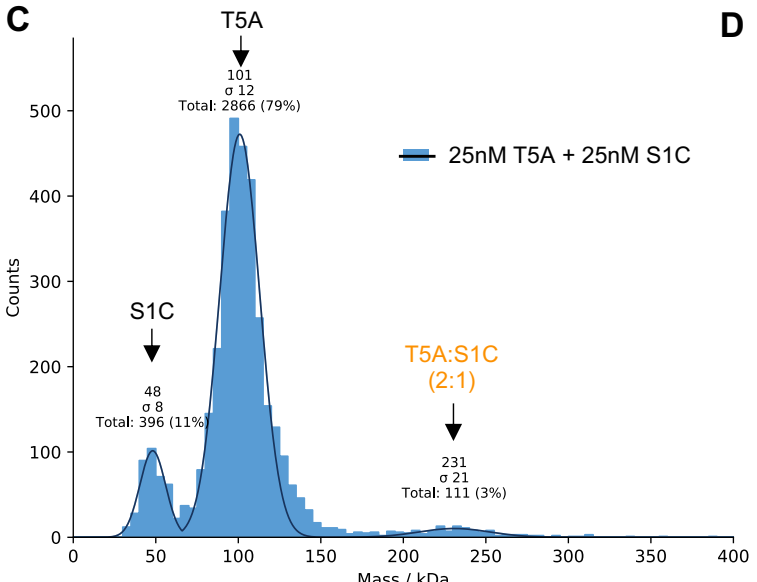

B
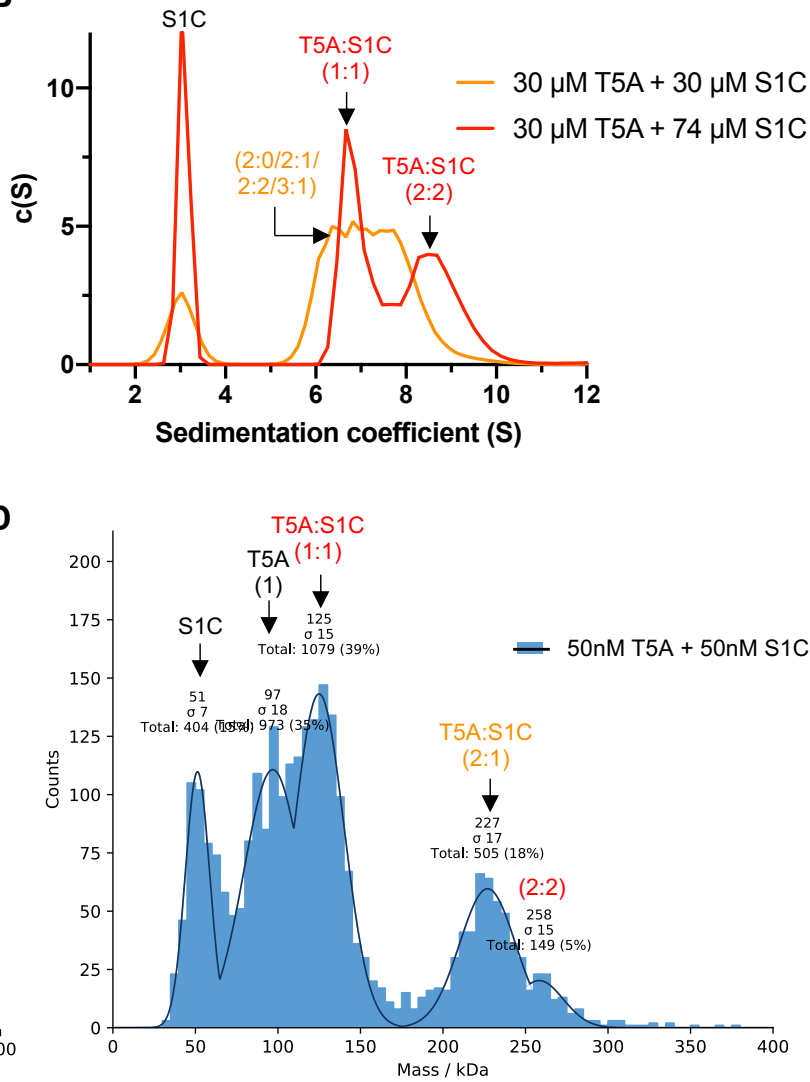

Figure 4: Slow exchanges in receptor-receptor interactions in the absence of ligand contrast with fast dynamics in the presence of ligand. AUC sedimentation velocity profiles and the shifts in sedimentation coefficients are indicative of dynamical behaviour or the receptor in the presence and the absence of its ligand (AB). Mass photometry (C-D) reveals the concentration-dependent stoichiometries of Toll5A and Spz1C. The singleligated Toll5A dimer is detected at the lowest measurable concentration of $25 \mathrm{nM}(\mathrm{C})$, whereas saturated dimer and ligated monomer appear at $50 \mathrm{nM}$ and above (D).

To determine whether these conformers are present for mosquito proteins at more physiological concentrations of ligand, we measured the composition of Toll5A-Spz1C mixtures at nanomolar concentrations using mass photometry (Fig. 4C-D). Our experimental setting was able to measure accurately molecules and complexes above $60 \mathrm{kDa}$, while free Spz1C was below the threshold, which resulted in erroneous mass determination. At $25 \mathrm{nM}$ Toll5A in the presence of $25 \mathrm{nM}$ Spz1C, Toll5A is predominantly monomeric but a 2:1 complex is detected along a species at $48 \mathrm{kDa}$, corresponding most likely to Spz1C. By contrast, at $50 \mathrm{nM}$ Toll5 in

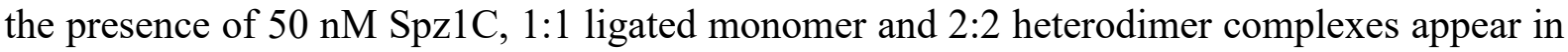
addition to Toll5A monomer and 2:1 complex. Hence, mass photometry detects stoichiometric conversions in non-equilibrium conditions. Toll5A homodimer is not detected consistent with the AUC data that suggests a $\mathrm{K}_{\mathrm{D}}$ value for this interaction in the $\mu \mathrm{M}$ range. None of these 
techniques detected the heterotrimer, which is therefore most likely a side effect of cryo-EM's capacity of visualising transition intermediates.

\section{Spz1C activates the production of antimicrobial peptides in Aag2 cells.}

In order to assay the activity of Spz1C, we stimulated the Aedes aegypti cell line Aag2, which constitutively expresses Toll5A (Fig. S7), with either full-length Spz1C proprotein or processed forms and Gram-negative bacteria for IMD pathway stimulation, as a positive control for a potent innate immune response. RT-qPCR was used to measure the induction of a range of antimicrobial peptides.

Aag2 cells do not up-regulate antimicrobial peptides (AMP) upon stimulation with pro-Spz1C. In contrast, processed Spz1C potently stimulated the production of several antimicrobial peptides including Defensin 1, Cecropin A, Glycine-rich repeat protein (GRRP) holotricin and Attacin B, (Fig. 5A). This activation overlaps but is distinct to that induced by a soluble extract of heat inactivated Gram-negative bacteria (GNB), which in addition activates the production of Gambicin, a general-purpose AMP. Neither GNB or Spz1C triggers the production of Vago, which is regulated by the RNA interference pathway, or Diptericin, an AMP potently induced by GNB in Drosophila via the IMD pathway (Tanji et al., 2007).

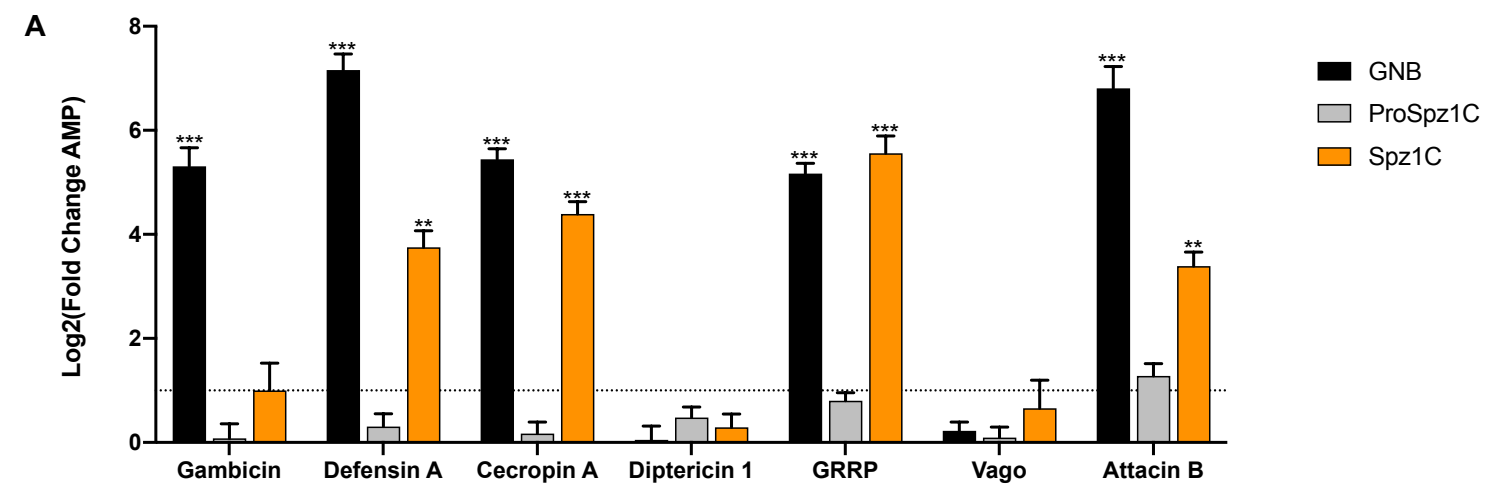

B

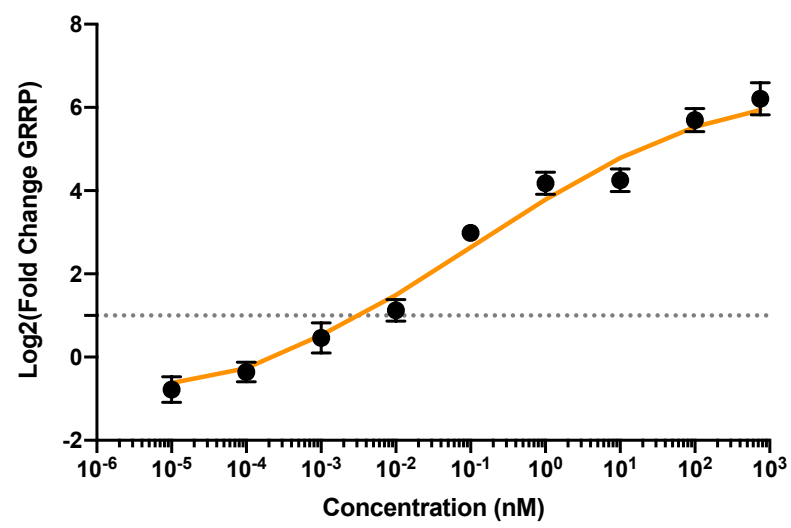

C

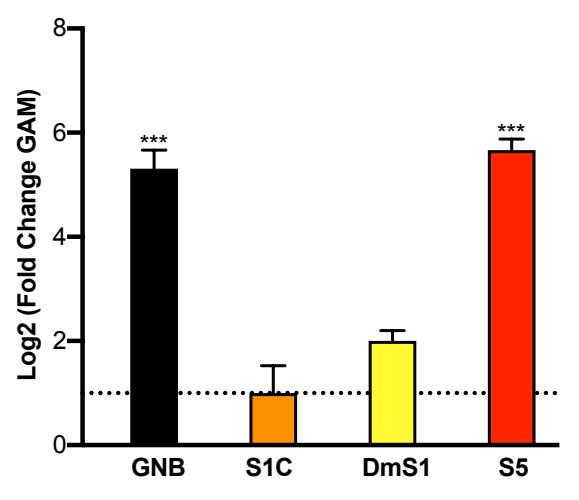

Figure 5: Spz1C activates a set of antimicrobial peptides (A), over a large range of concentrations (B), and in an isoform-specific manner (C). Expression of anti-microbial peptides in Aag2 cells at 12 hours after stimulation with Spz1C (proS1C and S1C: before and after cleavage of the prodomain, respectively) upon addition of purified protein in the media and RT-qPCR. Expression values were determined using the $\Delta \Delta \mathrm{CT}$ method with normalisation to mRNA levels of the eEFG1a housekeeping gene. The grey line indicates a value of Fold Change $=2$ as we determined to the limit to have change in expression profile. Statistical analyses were performed using Student T-test or two-sided Kruskal-Wallis test (according to application condition of each) to compare 
result versus a $\mathrm{FC}>2$. Data are mean \pm s.e.m. $(\mathrm{n}=3$ ). (B) Kinetics curves of GRRP expression in Aag2 cells after stimulation with different concentration of SpzlC (S1C). The fitted curve (in orange) represents smoothed conditional means calculated by ggPlot 2 on $\mathrm{R}$. The grey line indication a $\mathrm{FC}=2$ and Data are mean \pm s.e.m. $(\mathrm{n}=3)$. Heat-inactivated E.coli extract (GNB) was used as a positive control and conditioning buffer was used as a negative control.

Next, we assayed production of GRRP holotricin, an AMP that is strongly induced by Spz1C, in a dose-response experiment (Fig. 5B). Activation of holotricin expression occurs over a wide range of concentrations with an $\mathrm{EC}_{50}$ at sub-nanomolar concentrations. Furthermore, Spz1C signalling displays the same hallmarks of negative cooperativity observed in the Drosophila pathway, with $10 \%$ to $90 \%$ maximal signalling requiring an increase in ligand concentration of about 600 -fold.

Interestingly, we found that different Spz paralogues have different signalling activities, as suggested by the capacity of Aedes aegypti Spz5 to potently activate gambicin (GAM) (Fig. 5C). While Drosophila Spz1 is able to stimulate GAM moderately in Aag2 cells, this property is not shared by Spz1C. In Drosophila, Spz5 is recognised by Toll1, Toll6 and Toll7 (Chowdhury et al., 2019; Foldi et al., 2017; Nonaka et al., 2018). Given that Aag2 cells express other members relating to the Toll family of receptors (Fig. S7), it is conceivable that one of them triggers GAM activation reflecting its ligand specificity as opposed to the documented promiscuity of the Drosophila system.

\section{Spz1C regulates expression of genes involved in immunity and homeostasis}

We have used RNASeq to define the transcriptomic signature linked to Spz1C and compare it to activation of the immune system by Gram-negative bacteria and purified DAP-PGN, which in Drosophila activates the IMD signalling pathway. As shown in Fig. 6 there are 85 genes regulated by Spz1C, of which 83 are up-regulated and only 2 are down-regulated. These include GRRP holotricin, confirming its role as a marker of Spz1C, as well as other molecules linked to complement and immunity. Many genes encoding Clip Serine proteases, Serpins and Gramnegative Binding Protein (GNBP) are upregulated. In Drosophila these proteins function in peptidoglycan recognition and proteolytic cascades that activate Spz.

The Patched 1 (Ptc1) 7-TM receptor is strongly induced with potential implications for tissue regeneration (Lum and Beachy, 2004). The ligand for Ptc1 is Hedgehog, a morphogen involved in embryonic segmentation. This signalling pathway also plays a crucial role in maintaining adult tissue homeostasis. It is not known whether Ptc1 functions in insect immunity. Another upregulated gene encodes a putative ecdysone inducible protein ortholog L2 and is homologous to Drosophila Imaginal morphogenesis protein-Late 2 (IMPL2) (Roed et al., 2018), which is involved in the regulation of metabolism, growth, reproduction and lifespan. Two genes are down-regulated: Fatty Acyl-CoA Reductase (FAR) and the prostaglandin EP4 receptor. Interestingly, eicosanoid biosynthesis is controlled by the Toll pathway in some insects and also human PGE2 triggers a negative feedback loop, in which TLR4 signalling is restricted (see discussion). 


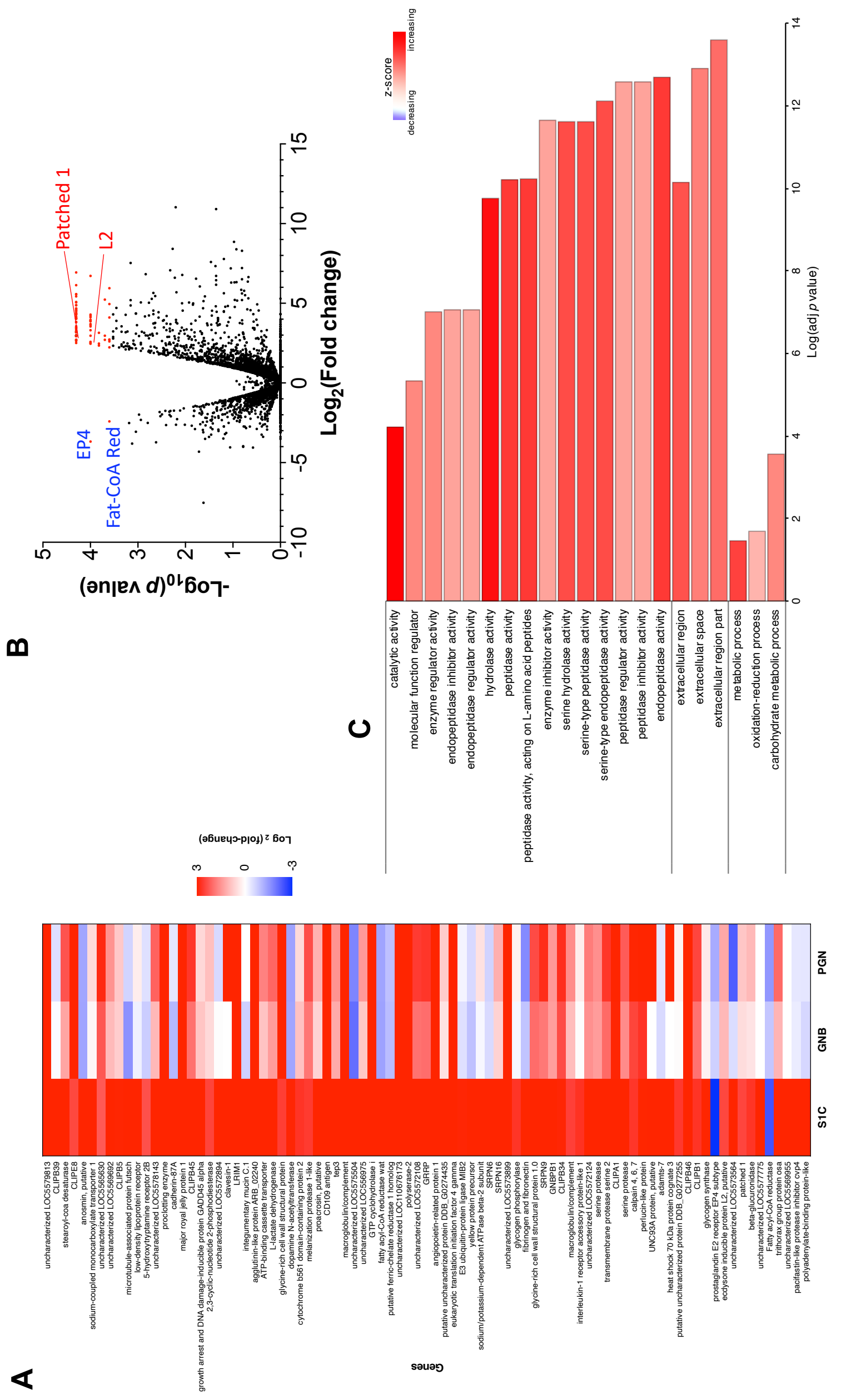


Figure 6: Spz1C transcriptional signature in Aag2 cells includes innate immune and metabolic genes that confer homeostasis and possibly, viral tolerance. RNAseq analysis.

(A) Genes exhibiting different response to stimulation with S1C heat map with indication of gene names normalized on MOCK stimulated Aag2 cells expression. These genes expression where also showed for GramBacteria and PGN stimulation. (B) Enriched GO categories associated with DEGs shown in (C). BP-biological processes, CC-cellular components, MF-molecular functions. (D) Significantly up-regulated (in red) and downregulated mosquito genes (in blue) upon stimulation with S1C compared with mock. Labelled genes where unique to S1C condition compared to other condition. All statistical tests were performed on $\mathrm{R}$ with a p-value $>$ 0.05 . Stars indicate significance: $*=$ p-value $<0.05, * *=p$-value $<0.01$, and $* * *=p$-value $<0.001$.

\section{Bioinformatic analysis supports neofunctionalization.}

In mosquitoes, immune-related gene families involved in pattern recognition and effector activity have increased compared to Drosophila as a result of gene duplication and family expansion (Waterhouse et al., 2007). In contrast, cytosolic signal transducers such as MyD88 tend to have a stricter orthology. At the interface between both are transmembrane receptors and their ligands. Spzl is the only ligand that has diversified in A. aegypti with genetic evidence pointing towards a specific role for Spz1C in mosquito immunity. In particular, Spz1C together with Toll5A mediate anti-fungal immunity (Shin et al., 2006). More importantly, Dengue virus upregulates Spz1C in the midgut (Wang et al., 2019) and Toll5A in the salivary glands (Luplertlop et al., 2011), hinting at a role in vector-virus interactions.

Mosquito Toll-1 and 5 receptors are between $32-41 \%$ identical to Drosophila Toll (DmToll1) and between 36 to $53 \%$ identical within the Aedes Toll-1/5 paralogue group. However, the extracellular domains alone are less well conserved $(27-35 \%)$. This contrasts with the nonduplicated receptors, which have sequence identities typically over $60 \%$. Upon closer inspection, Aedes aegypti Toll-1A, 1B and 5A have a precisely conserved number of leucinerich repeats (LRRs) and Cys-rich capping structures, comparable to the prototypical Drosophila Toll-1 receptor (Fig. S8A). On the other hand, Toll5B differs, with the gene being located on chromosome III and a shorter ectodomain with 15 LRRs instead of 17 at the N-terminus. The duplicated mosquito Toll-5 receptors also differ markedly from the Drosophila orthologue DmToll-5 called Tehao, which has $8 \mathrm{~N}$-terminal LRRs and fewer cysteine residues. No ligand for DmToll-5 has been identified so far. We note that its ectodomain lacks features involved in DmToll-1 ligand binding. Nevertheless DmToll-5 can induce the production of antimicrobial peptides when overexpressed in cell culture and forms heterodimers with DmToll-1 (Luo et al., 2001).

The duplicated $\mathrm{Spz} 1$ genes in Aedes have also diverged considerably from Drosophila with only 21-31\% sequence identity among orthologues. Non-duplicated $S p z$ vary from $35 \%$ for $S p z 2$ to $89 \%$ for Spz6. The C-terminal active fragment containing the Cys-knot domain follows the same trend and displays sequence identities around 64-88\% for 1-to-1 orthologues, and 25$33 \%$ for duplicated $S p z 1$. The direct orthologue of $\mathrm{DmSpzl}$ is predicted to be $S p z X$ in A. aegypti. $S p z X$ also conserves the patterns of alternative splicing seen for DmSpzl including transcripts with a truncated Cys-knot $(S p z X-G)$ (Parker et al., 2001) (Fig. S8B). However, $S p z X$ represents the amalgamation of two different Cys-knot sequences previously annotated $S p z 1 A$ and $S p z 1 B$, now gathered in one locus that undergoes alternative splicing (Dudchenko et al., 2017; Nene et al., 2007; Shin et al., 2006). Remarkably, four splice forms $S p z X-D / E / I / J$, have Cys-knot domain sequences identical to $S p z 1 A$ but gained an additional C-terminal furin cleavage site. $S p z X-D$ and $E$ acquired an additional furin site in the prodomain (not shown). $S p z X-F, S p z 1 C$ and $D m S p z l$ do not have furin recognition sites, which are the hallmark of neurotrophins, such as $S p z 2$ and Spz5 (Foldi et al., 2017). 
Structurally, SpzX-F/C/H have lost the conserved Cys residue involved in the formation of the intermolecular disulphide bonding (Fig. S8B). Instead, they have a cysteine residue in an alternative location that is predicted to form an inter-molecular disulfide bond located at the ligand-receptor interface. This residue is shared by Spz3/4/5 and Spz1C. The structure of Spz1C confirms the presence of two intermolecular disulphide bridges that constrain the covalent cystine-knot dimer doubly.

Interestingly, OrthoMCL-DB congregated Aedes SpzX and Drosophila Spzl genes into an ortholog group based on their sequence similarity (OG6_117926). SpzlC however is excluded from this group and forms a group on its own (OG6 426965). Next, we checked if SpzlC was restricted to the $A$. aegypti lineage. When this study was initiated, it seemed to have no counterpart in any of the sequenced organisms. It therefore appeared to be a lineage-restricted gene. A. albopictus, which diverged only $\sim 71$ Mya from A. aegypti, has recently been resequenced (Palatini et al., 2020). Interestingly, the updated genome of $A$. albopictus contains 3 copies of SpzlC-like genes at loci LOC109412940, LOC109424625 and LOC115260685. Hence, Spz1C has undergone Aedes-specific duplication and a rapid expansion in A. albopictus, whereas Toll1/5 sequences all appear to cluster in the same ortholog group (OG6_106857).

\section{Discussion}

In this study we show that the haematophagous mosquito $A$. aegypti has a duplicated Toll ligand, Spz1C, that specifically activates the Toll5A paralogue with low affinity. A. aegypti diverged from A. gambiae, which is the main vector for malaria, about $217 \mathrm{Myr}$ ago and adapted to become an efficient vector for flaviviruses such as Dengue viruses, as evident from the large number of non-retroviral integrated RNA viruses present in the $A$. aegypti but not the $A$ gambiae genome. Interestingly, the Asian tiger mosquito A. albopictus, which diverged from A. aegypti more recently, further expanded $S p z 1 C$ genes. In contrast, more divergent species from the Anopheles and Culex genera, which are not (or less) competent to vector these viruses, do not possess this paralog. Assuming the available mosquito genomes have been reliably sequenced, the presence of $\mathrm{SpzlC}$ genes might therefore be an indicator of vectorial competence enabling flaviviruses to exist symbiotically at high titre in mosquitoes.

Our biophysical characterisation shows that Spz1C binds specifically to Toll5A with micromolar affinity compared to the nanomolar binding of DmSpzl by DmToll1. DmSpz1 is also able to bind promiscuously to DmToll6 and DmToll7 and so it may be that low affinity binding confers signalling specificity for Toll5A. Consistent with this idea the Aedes Spz5 paralog but not Spz1C activates the AMP gambicin in Aag2 cells as strongly as bacterial extracts while DmSpzl induces a partial activation (Fig. 5C). Thus A. aegypti has evolved a tiered Toll mediated immune system compared to Drosophila where Toll1 alone fulfils most immune functions.

Low affinity ligand binding and its ramifications in terms of signalling has been extensively characterised for mammalian cytokine receptors for interferons and interleukin ligands (Levin et al., 2011; Moraga et al., 2015, 2009). Such cytokines display pleiotropic effects while inducing a spectrum of redundant and yet distinct cellular functions. Receptor-ligand association and dissociation rates (kon and $k_{0}$ f) have been found to be key in determining signalling outcomes. On-rates determine the amount of STAT transcription factor activation upon controlling the number of ligand-receptor complexes formed at the plasma membrane. In contrast, off-rates correlate to the kinetics of STAT activation depending on the half-life of ligand-receptor complexes. Alternatively, cell surface abundance of cytokine receptors plays a major role in triggering different transcriptional programs and cell fates, through obeying the 
mass action law and titrating cytokine concentrations. Our hypothesis in the case of Aedes Toll5A and Spz1C is that cell fate will be regimented in two ways depending on receptor and ligand concentrations: (i) ligand concentration will change the intensity of the signal (increased Spz1C for increased antimicrobial peptide production as illustrated in Fig.5); and (ii) increased receptor density will promote inhibitory self-association leading to immune quiescence.

The structures we present provide a plausible molecular explanation for negatively cooperative signalling. Binding of the first Spz1C homodimer to form the asymmetric complex can occur transiently at relatively low ligand concentrations but the 2:2 form would be even lower affinity, and hence only form at higher ligand concentrations. There are two classical theoretical models of sequential binding that lead to negatively cooperative receptor signalling as initially proposed by Koshland in the 1960's (Koshland, 1996; Levitzki and Koshland, 1969). Thus, binding of the first monomeric ligand to a dimeric receptor partially activates signalling but full activation requires the less favourable binding of the second ligand monomer. In the second model the binding of two monomeric ligands to form a 2:2 complex is required for signal transduction. The two models lead to somewhat different theoretical stimulus-response curves and our experiments appear to fit better with Model 1 for the production of antimicrobial peptides (Fig. 5). If the ligand is limiting there is an ultrasensitive response with a pronounced threshold, more reminiscent of positive than negative cooperativity (Ha and Ferrell, 2016). In our cell culture assays, Spz1C is likely not limiting, however this phenomenon may be relevant for development and homeostasis controlled by Spz in the whole organism.

The activation profile of Spz1C differs from Drosophila Spz1 and Aedes Spz5, despite their shared cystine-knot fold, having a transcriptomic profile that indicates functions that go beyond immunity. Spz1C specifically activates the production of Hedgehog receptor, insect insulinbinding protein L2 and genes involved in reprogramming fatty acid metabolism. If Spz1C and Toll5A were both upregulated in the salivary glands, and achieved the double ligated state as suggested by Bonizzoni et al. (Bonizzoni et al., 2012), it is also conceivable that Spz1C and its receptor could be involved in viral tolerance by promoting lipid metabolism and homeostasis. The mechanism of action may differ in the midgut where Spz1C expression is induced to limit viral invasion, an immunological role (Luplertlop et al., 2011). By contrast in the salivary gland (Wang et al., 2019), where Toll5A up-regulation may increase avidity for the ligand, a double ligated and hence fully saturated receptor complex might lead to a signal that differs from low density single-ligated receptors. Hence, future studies need to tackle the signalling capacities of 2:1 and 2:2 complexes via detecting the recruitment of MyD88 first, and if so, by checking if different sets of genes are controlled by both type of complexes. Fluorescence microscopy experiments will be best suited to detect such complexes along the presence of unliganded receptor homodimers to distinguish between these models.

Remarkably and despite a significantly lower affinity, Spz1C is as potent in stimulating mosquito Aag2 cells, as DmSpz is at stimulating Drosophila S2 cells. An alternative explanation is that cleavage of the Z-loop promotes stable ligand binding and thus processing might account for the discrepancy between protein affinity and cellular potency of Spz1C. On the other hand, Spz1C binding prevents cleavage of Toll5A of the Z-loop, a finding that is not consistent with the Z-loop impeding ligand binding. Additionally, we expressed Toll5A in insect cells without detecting such processing, which likely rules out its spontaneous occurrence in our view. However, Drosophila Toll1 can be cleaved at an equivalent residue, Asp 458 and forms a stable dimer with the ectodomain remaining intact (Weber et al., 2005). Taken together, we conclude that this region is critical for promoting ligand-induced dimerization while the physiological relevance of its processing requires further examination. Of note, the nucleic-acid 
binding TLRs that are also activated by endoproteolytic cleavage display positive cooperativity (Leonard et al., 2008).

In light of the above it is likely that there will be a degree of synergy between Toll5A signalling and the vectorial capacity of Aedes aegypti. Our study sheds new light on Toll signalling, while raising fundamental questions. Do Toll receptors undergo endoproteolytic processing to regulate their activity? Which oligomeric forms occur in vivo and what are their respective signalling outputs? More importantly, can SpzlC signalling be exploited to fight mosquitoborne diseases? If so, the structural data in hand can guide future transmission-blocking strategies.

\section{ACKNOWLEDGMENTS}

We thank Drs Katherine Stott, Biophysics Facility manager, and Paul Brear for training in biophysical techniques and continuous support; Drs Marko Hyvönen and Joseph Maman, for helpful discussions. We also thank Joe for training in SEC-MALS and Dr Nathan Cowieson, for supporting the SEC-SAXS at B21 Diamond Light Source. We thank Shilo Dickens, DNA sequencing facility manager, and her team, in particular, Dr Markiyan Samborskyy, for RNAseq analysis. We thank Tom Dendooven for sharing the protocol for cryo-EM sample preparation used in this study, and Lee Cooper for Vitrobot training and cryo-EM grid preparation. This work is supported by a New Investigator grant from the Medical Research Council to M.G. (MR/P02260X/1).

\section{AUTHOR CONTRIBUTIONS}

M.G. and Y.S. designed biochemical experiments. M.G, S.G.S and Y.S. planned cell assays. M.G., Y.S., and T.H.W. purified and assembled complexes. M.C.M performed AUC experiments. S.H. and D.Y.C. collected and processed cryo-EM data. M.G. performed model building and structure refinement. M.J.M. carried out MP experiments and analysed SECSAXS data. M.G. analysed structural and functional data and wrote the manuscript with the help of N.J.G. and M.C.M.

\section{DECLARATION OF INTERESTS}

The authors declare no competing interests.

\section{MATERIALS AND METHODS}

\section{Bioinformatic analysis}

Mosquito Toll and Spz sequences were retrieved via BLAST searches in Uniprot (Bateman et al., 2021) and Vectorbase (Giraldo-Calderón et al., 2015). Sequence alignments were performed using Muscle (Edgar, 2004). Homology modelling was carried out using Modeller (Webb and Sali, 2014). Alignments were visualised in Jalview (Waterhouse et al., 2009) and 3D-models in PyMol (Molecular Graphics System) and Chimera (Pettersen et al., 2004). 


\section{DNA Constructs}

Constructs were either derived from genomic or synthetic DNA upon codon optimisation to improve the protein production yields for Toll1A (Vectorbase identifier AAEL026297), Toll5A (AAEL007619), Spz1A (UniProt accession code Q17P53), Spz1C (UniProt accession code Q16J57; Vectorbase identifier AAEL013433) and SpzX (AAEL013434). Constructs were cloned into baculovirus transfer vector pFast-Bac1 within BamHI and NotI, and into pMT-V5His $_{\mathrm{A}}$ within KpnI and NotI (ThermoFisher).

\section{Cell culture}

Aag2 cells were a kind gift from Alain Kohl (University of Glasgow, UK), and were maintained in Schneider's Insect Medium with L-glutamine and sodium bicarbonate (Merck KGaA, Darmstadt, Germany) supplemented with $10 \%$ (v/v) foetal bovine serum (FBS - Sigma-Aldrich, USA), $100 \mathrm{U} / \mathrm{ml}$ penicillin and $100 \mu \mathrm{g} / \mathrm{ml}$ streptomycin at $28^{\circ} \mathrm{C}$ in a humidified atmosphere without $\mathrm{CO}_{2}$.

SF9 cells (ThermoFisher) used for baculovirus preparation and were maintained in InsectXPRESS $^{\mathrm{TM}}$ Protein-free Insect Cell Medium with L-Glutamine (Lonza) at $28^{\circ} \mathrm{C}$ under agitation. S2 cells used for stable insect expression were also maintained in Insect-XPRESS ${ }^{\mathrm{TM}}$ Protein-free Insect Cell Medium with L-Glutamine at $28^{\circ} \mathrm{C}$ with or without agitation.

\section{Protein production and purification}

\section{Spz Proprotein and Cys-knot domain preparation}

A. aegypti Spz paralogues were produced in a baculovirus expression system (Bac-to-Bac, ThermoFisher) with a C-terminal Strep-tag $®$ II with or without an engineered TEV-cleavage site between the prodomain (Spz1C prodomain residues 43-218) and the Cystine-knot domain (Spz1C residues 219-320) after establishing the domain boundaries using limited trypsin proteolysis.

Typically, 4 litres Sf9 at 2 million cells per $\mathrm{ml}$ were infected at a MOI $=2.0$ and cultured under agitation at $19{ }^{\circ} \mathrm{C}$ instead of $27{ }^{\circ} \mathrm{C}$ for optimal expression over 5 days. The supernatant was harvested after removing cells by centrifugation at $2,000 \mathrm{~g}$ for $10 \mathrm{~min}$ and filtered on a Sartobran P sterile capsule of $0.45 \mu \mathrm{m}$ (Sartorius). The buffer was then exchanged to buffer A $(150 \mathrm{mM} \mathrm{NaCl}, 100 \mathrm{mM}$ Tris-HCl, $\mathrm{pH} 7.5,1 \mathrm{mM}$ EDTA) and concentrated to $500 \mathrm{ml}$ using a Centramate tangential flow filtration system (Pall). It was loaded on a Strep-Tactin ${ }^{\circledR X T}$ Superflow ${ }^{\circledR}$ resin (IBA) following manufacturer recommendations. The resin was equilibrated in 10 column volumes of buffer A prior to use and subsequently washed with 10 column volumes of the same buffer to remove non-specifically bound proteins. Strep-tagged protein was eluted in buffer A containing $50 \mathrm{mM}$ biotin. Peak fractions were pooled and purified by anion-exchange on a $5 \mathrm{ml}$ Hitrap Q (Cytiva, formerly GE Healthcare Life science) in a $\mathrm{NaCl}$ gradient from $50 \mathrm{mM}$ to $1 \mathrm{M}, 50 \mathrm{mM}$ Tris- $\mathrm{HCl}, \mathrm{pH} 7.5$, followed by size exclusion chromatography on a Superdex 75 10-300 GL column (Cytiva) at $0.5 \mathrm{ml} / \mathrm{min}$ in buffer C: 50 $\mathrm{mM} \mathrm{NaCl}, 50 \mathrm{mM}$ Tris-HCl, $\mathrm{pH}$ 7.5. Fractions were analysed by Coomassie-stained SDSPAGE. Protein concentrations were quantified by absorption at $280 \mathrm{~nm}$. A typical yield was 3 mg of purified protein per litre of cell culture. Drosophila Spz production has been described elsewhere (M. Gangloff et al., 2008). 


\section{Toll ectodomain preparation}

A stable Schneider 2 cell line containing pMT-V5/His-A A. aegypti Toll1A (AAEL026297) ectodomain (residues 1-835) and Toll5A (AAEL007619) ectodomain (residues 1- 789), a Cterminal TEV-cleavable Protein A fusion and a Flag-tag was induced with copper sulfate 0.5 $\mathrm{mM}$ at 3 million cells $/ \mathrm{ml}$. Cells were cultured at $27^{\circ} \mathrm{C}$ under agitation and harvested after 3-4 days. Culture supernatant were filtered, buffer-exchanged and concentrated to $0.5 \mathrm{~L}$ in $150 \mathrm{mM}$ $\mathrm{NaCl}, 50 \mathrm{mM}$ Tris- $\mathrm{HCl} \mathrm{pH} 7.5,0.05 \%$ Tween 20. Protein A Flag tagged proteins were isolated with IgG Sepharose ${ }^{\circledR} 6$ Fast Flow (Cytiva), incubated with TEV protease at a 1:10 (w/w) ratio at $4^{\circ} \mathrm{C}$ overnight in $150 \mathrm{mM} \mathrm{NaCl}, 50 \mathrm{mM}$ Tris-HCl, $\mathrm{pH} 7.5$ (buffer D). TEV-cleaved proteins lacking Protein A-Flag tag were collected in the flow through upon washing in buffer D. Protein A eluted in $0.1 \mathrm{M} \mathrm{Na}$ Acetate $\mathrm{pH}$ 3.4. Fractions of interest were pooled and further purified by anion-exchange (as above) and size exclusion chromatography on a Superdex 200 10-300 GL column (Cytiva) at $0.5 \mathrm{ml} / \mathrm{min}$ in buffer $\mathrm{C}$.

\section{Surface plasmon resonance}

SPR experiments were performed on a Biacore T200 instrument with dextran-based Sensor Chip CM5 (Cytiva) in $100 \mathrm{mM} \mathrm{NaCl}, 20 \mathrm{mM}$ HEPES pH 7 running buffer and a flowrate of 30 $\mu \mathrm{l} /$ minute. The chips were activated by 1-Ethyl-3-(3-dimethylaminopropyl)-carbodiimide hydrochloride and $N$-hydroxysuccinimide, and Spz1 A, Spz1C and DmSpz proproteins and cysknot ligands were immobilized by amine coupling at $\mathrm{pH} 4.5$. Sensorgrams were recorded and corrected by subtraction of control signal from an empty flow cell. Purified ectodomain analytes of Toll1A, Toll5A and DmToll were injected at concentrations between 0.1 to $7.5 \mu \mathrm{M}$ in tenfold dilution series. Kinetic analysis was performed by fitting sensorgrams to a two-state reaction model.

\section{Analytical ultracentrifugation}

Analytical ultracentrifugation experiments were performed on an Optima XL-A/I (Beckman Coulter) centrifuge equipped with a four-hole titanium rotor, double-sector centrepieces, and an interference optical system for data acquisition. Sedimentation velocity runs were performed at 50,000 rpm with 3-min intervals between scans for a total of 190 scans at $20^{\circ} \mathrm{C}$. The sample volume was $400 \mu \mathrm{L}$. Data were analysed using Sedfit software (Schuck, 2000). The partial specific volumes, buffer density, and viscosity were estimated using SEDNTERP software (Laue TM, Shah BD, Ridgeway TM, 1992).

\section{SEC-MALS}

Size exclusion chromatography-coupled multi-angle light scattering (SEC-MALS) was used to analyse protein monodispersities and molecular weights. SEC was performed using an Äkta Purifier (GE Healthcare) and a Superose 6 10/300 GL column (GE Healthcare) in $50 \mathrm{mM}$ Tris$\mathrm{HCl} \mathrm{pH} 7.5,50 \mathrm{mM} \mathrm{NaCl}$. For each measurement, $50 \mu \mathrm{L}$ of protein at a given concentration was injected and gel filtrated at a flow rate of $0.5 \mathrm{ml} /$ minute. Light scattering was recorded using a miniDAWN TREOS instrument (Wyatt Technology). Protein concentration in each elution peak was determined using differential refractive index (dRI). The data were analysed using the ASTRA 6.2 software (Wyatt Technology). 


\section{SEC-SAXS}

SAXS measurements were performed at Diamond Light Source (Oxfordshire, UK), beamline 21 (B21) (Cowieson et al., 2020) at a wavelength $0.89-1.3 \AA$ with a sample to detector distance of $3.7 \mathrm{~m}$ and a Eiger $4 \mathrm{M}$ (Dectris) detector, covering a momentum transfer of $0.0026<q>0.34$ $\AA^{-1}[q=4 \pi \sin \theta / \lambda, 2 \theta$ is the scattering angle]. The proteins were analysed by size-exclusion chromatography in line with small-angle X-Ray scattering (SEC-SAXS) to avoid the signal from possible aggregates. The samples were applied to a Superose 6 Increase 3.2/300 column (Cytiva) at a concentration of $5 \mathrm{mg} / \mathrm{ml}$ and run at a flow rate of $0.075 \mathrm{ml} / \mathrm{min}$ in $50 \mathrm{mM}$ Tris$\mathrm{HCl}, \mathrm{pH} 7.5,50 \mathrm{mM} \mathrm{NaCl}$. SAXS measurements were performed at $20^{\circ} \mathrm{C}$ using an exposure time of $3 \mathrm{~s}_{\text {frame }}{ }^{-1}$. SAXS data were processed and analysed using the ATSAS program package version 2.8.3 (Franke et al., 2017) and ScÅtter (www.bioisis.net). The radius of gyration $R_{\mathrm{g}}$ and forward scattering $I(0)$ were calculated by Guinier approximation. The maximum particle dimension $D_{\max }$ and $P(r)$ function were evaluated using the program GNOM (Svergun, 1992).

\section{Mass Photometry}

All mass photometry measurements were executed on a Refeyn OneMP instrument. The calibration was done with a native marker protein standard mix (NativeMark Unstained Protein Standard, Thermo Scientific), which contains proteins ranging from 20 to 1,200 kDa. Coverslips $(24 \times 50 \mathrm{~mm}$, No. $1.5 \mathrm{H}$, Marienfeld $)$ were cleaned by sequential sonication in Milli$\mathrm{Q}$ water, isopropanol and Milli-Q-water, followed by drying with nitrogen. For each acquisition $2 \mu \mathrm{L}$ of protein solution was applied to $18 \mu \mathrm{L}$ PBS buffer, $\mathrm{pH} 7.4$ in a gasket (CultureWellTM Reusable Gasket, Grace Bio-Labs) on a coverslip. Increasing working concentrations tested included 25, 50, 75 to $100 \mathrm{nM}$. Movies were recorded at $999 \mathrm{~Hz}$ with an exposure time of 0.95 ms by using the AcquireMP software. All mass photometry movies were processed and analysed in the DiscoverMP software. Samples were measured in duplicates.

\section{Cryo-EM}

Holey carbon grids (Quantifoil Cu R1.2/1.3, 300 mesh) were glow discharged for $60 \mathrm{sec}$ at current of $25 \mathrm{~mA}$ in PELCO Easiglow (Ted Pella, Inc). Aliquots of $3 \boldsymbol{\mu l}$ of between $3-6 \mathrm{mg} / \mathrm{ml}$ of Toll5A-Spz1C gel-filtered complex mixed with $8 \mathrm{mM}$ CHAPSO (final concentration, Sigma) were applied to the grids, which were immediately blotted with filter paper once to remove any excess sample, and plunge-frozen in liquid ethane using a FEI Vitrobot Mark IV (Thermo Fisher Scientific Ltd) at $4{ }^{\circ} \mathrm{C}$ and $95 \%$ humidity. All cryo-EM data presented were collected eBIC (Harwell, UK) and all data collection parameters are given in Table S1.

Cryo-EM images were processed using Warp (Tegunov and Cramer, 2019) and CryoSPARC (Punjani et al., 2017). In short, CTF correction, motion correction, and particle picking were performed using Warp. These particles were subjected to two-dimensional (2D) classification in CryoSPARC followed by ab initio reconstruction to generate initial 3D models. Particles corresponding to different classes were selected and optimised through iterative rounds of heterogeneous refinement as implemented in CryoSPARC. The best models were then further refined using homogenous refinement and finally non-uniform refinement in CryoSPARC. Finally, all maps were further improved using ResolveCryoEM in PHENIX (Terwilliger et al., 2019).

The final cryo-EM maps following density modification were used for model building. The crystal structures of Drosophila Toll and Spz were used to generate the homology model of 
Aedes Toll5A and Spz1C using Modeller (Webb and Sali, 2014). The initial model was then rigid-body fitted into the cryo-EM density for the highest resolution map of the apo-dimer of Toll5A in UCSF chimera (Pettersen et al., 2004) and manually adjusted and rebuilt in Coot(Emsley et al., 2010). Namdinator (Kidmose et al., 2019) was used to adjust the structure and several rounds of real space refinement were then performed in PHENIX (Afonine et al., $2018 \mathrm{~b}$ ) before the final model was validated using Molprobity (Afonine et al., 2018a). For Toll5A in the holo-dimer and the 3:1 trimer cryo-EM maps, the initial model for the receptor was taken from the apo-dimer refined structure, while Spz1C was the Drosophila Spz homology model and the same strategy was applied. All structures were refined and validated before being deposited into the PDB.

\section{RNA sequencing and RT-qPCR}

Total cellular RNA was extracted using the RNeasy Mini Kit (Qiagen, Germany) following manufacturer recommendations. Contaminating DNA was removed using TURBO DNA-free Kit (ThermoFisher Scientific, USA). The quantity and quality of RNA was checked using a NanoDrop spectrophotometer (ThermoFisher) and Bioanalyzer for RNA sequencing samples. Library preparation was performed with TruSeq Stranded mRNA Library Prep Kit (Illumina). Sample sequencing was performed on an Illumina NextSeq 500 using mRNA derived from different conditions (Mock Aag2 cells and stimulated with 100nM of Spz1C, GNB and PGN). The reads obtained by RNA-seq were analysed using the Cufflinks RNA-Seq workflow against A. aegypti genome on VectorBase (www.vectorbase.org). All graphic representations were made using CummeRbund package (v3.10) on R. RT-qPCR was conducted in a Rotor-Gene Q system (Qiagen) for over 40 cycles with an annealing temperature of $60{ }^{\circ} \mathrm{C}$, with each well containing $2 \mu \mathrm{l} \mathrm{RNA}(10 \mathrm{ng} / \mu \mathrm{l}), 0.8 \mu \mathrm{l} 10 \mu \mathrm{M}$ specific primers (final concentration, $300 \mathrm{nM}$ ), $5.4 \mu 1 \mathrm{H}_{2} \mathrm{O}, 1 \mu \mathrm{l}$ 20X Luna WarmStart RT Enzyme Mix (NEB) and $10 \mu \mathrm{l} 2 \mathrm{X}$ Luna Universal One-step Reaction mix (NEB). Samples were measured in triplicates. Assessment of the expression of each target gene was based on relative quantification (RQ) using the comparative critical threshold (CT) value method. The RQ of a specific gene was evaluated in each reaction by normalization to the CT obtained for endogenous control gene elongation factor 1 alpha (eEF1a). Three independent infection experiments were conducted. The primers for quantitative RT-PCR used in this study are presented in Table S3. Data were analysed by t-test, Mann-Whithney, Krustal Wallis or ANOVA test depending on the application conditions and $\mathrm{P}$ value of $<0.05$ was considered significant on $\mathrm{R}$ software.

\section{Quantification and statistical analysis}

Quantification and statistical analyses pertain to the analysis of cryo-EM data are integral parts of algorithms and software used.

\section{Data and code availability}

SAXS data were deposited at the Small Angle Scattering database with accession numbers SASDKX8 for Toll5A alone and, SASDKY8 for Toll5A with Spz1C, respectively. The cryoEM 3D maps corresponding to the apo-dimer, the holo-dimer and the holo-trimer were deposited in EMDB database with accession codes EMD-11984; EMD-11982 and EMD11983, respectively. The corresponding atomic models were deposited in PDB with accession codes 7B1D, 7B1B and 7B1C, respectively. 


\section{REFERENCES}

Afonine P V., Klaholz BP, Moriarty NW, Poon BK, Sobolev O V., Terwilliger TC, Adams PD, Urzhumtsev A. 2018a. New tools for the analysis and validation of cryo-EM maps and atomic models. Acta Crystallogr Sect D Struct Biol. doi:10.1107/S2059798318009324

Afonine P V., Poon BK, Read RJ, Sobolev O V., Terwilliger TC, Urzhumtsev A, Adams PD. 2018b. Real-space refinement in PHENIX for cryo-EM and crystallography. Acta Crystallogr Sect D Struct Biol. doi:10.1107/S2059798318006551

Arnot CJ, Gay NJ, Gangloff M. 2010. Molecular mechanism that induces activation of Sp??tzle, the ligand for the Drosophila toll receptor. J Biol Chem 285:19502-19509.

Bateman A, Martin MJ, Orchard S, Magrane M, Agivetova R, Ahmad S, Alpi E, BowlerBarnett EH, Britto R, Bursteinas B, Bye-A-Jee H, Coetzee R, Cukura A, Silva A Da, Denny P, Dogan T, Ebenezer TG, Fan J, Castro LG, Garmiri P, Georghiou G, Gonzales L, Hatton-Ellis E, Hussein A, Ignatchenko A, Insana G, Ishtiaq R, Jokinen P, Joshi V, Jyothi D, Lock A, Lopez R, Luciani A, Luo J, Lussi Y, MacDougall A, Madeira F, Mahmoudy M, Menchi M, Mishra A, Moulang K, Nightingale A, Oliveira CS, Pundir S, Qi G, Raj S, Rice D, Lopez MR, Saidi R, Sampson J, Sawford T, Speretta E, Turner E, Tyagi N, Vasudev P, Volynkin V, Warner K, Watkins X, Zaru R, Zellner H, Bridge A, Poux S, Redaschi N, Aimo L, Argoud-Puy G, Auchincloss A, Axelsen K, Bansal P, Baratin D, Blatter MC, Bolleman J, Boutet E, Breuza L, Casals-Casas C, de Castro E, Echioukh KC, Coudert E, Cuche B, Doche M, Dornevil D, Estreicher A, Famiglietti ML, Feuermann M, Gasteiger E, Gehant S, Gerritsen V, Gos A, Gruaz-Gumowski N, Hinz U, Hulo C, Hyka-Nouspikel N, Jungo F, Keller G, Kerhornou A, Lara V, Le Mercier P, Lieberherr D, Lombardot T, Martin X, Masson P, Morgat A, Neto TB, Paesano S, Pedruzzi I, Pilbout S, Pourcel L, Pozzato M, Pruess M, Rivoire C, Sigrist C, Sonesson K, Stutz A, Sundaram S, Tognolli M, Verbregue L, Wu CH, Arighi CN, Arminski L, Chen C, Chen Y, Garavelli JS, Huang H, Laiho K, McGarvey P, Natale DA, Ross K, Vinayaka CR, Wang Q, Wang Y, Yeh LS, Zhang J. 2021. UniProt: The universal protein knowledgebase in 2021. Nucleic Acids Res 49. doi:10.1093/nar/gkaa1100

Bonizzoni M, Dunn WA, Campbell CL, Olson KE, Marinotti O, James AA. 2012. Complex Modulation of the Aedes aegypti Transcriptome in Response to Dengue Virus Infection. PLoS One 7. doi:10.1371/journal.pone.0050512

Chen XG, Jiang Xuanting, Gu J, Xu M, Wu Y, Deng Y, Zhang C, Bonizzoni M, Dermauw W, Vontas J, Armbruster P, Huang X, Yang Y, Zhang H, He W, Peng H, Liu Y, Wu K, Chen J, Lirakisi M, Topalis P, Van Leeuwen T, Hall AB, Jiang Xiaofang, Thorpe C, Mueller RL, Sun C, Waterhouse RM, Yan G, Tu ZJ, Fang X, James AA. 2015. Genome sequence of the Asian tiger mosquito, aedes albopictus, reveals insights into its biology, genetics, and evolution. Proc Natl Acad Sci U S A. doi:10.1073/pnas.1516410112

Chowdhury M, Li CF, He Z, Lu Y, Liu XS, Wang YF, Tony Ip Y, Strand MR, Yu XQ. 2019. Toll family members bind multiple Spätzle proteins and activate antimicrobial peptide gene expression in Drosophila. J Biol Chem. doi:10.1074/jbc.RA118.006804

Christophides GK, Zdobnov E, Barillas-Mury C, Birney E, Blandin S, Blass C, Brey PT, Collins FH, Danielli A, Dimopoulos G, Hetru C, Hoa NT, Hoffmann JA, Kanzok SM, Letunic I, Levashina EA, Loukeris TG, Lycett G, Meister S, Michel K, Moita LF, Müller H-M, Osta MA, Paskewitz SM, Reichhart J-M, Rzhetsky A, Troxler L, Vernick KD, Vlachou D, Volz J, von Mering C, Xu J, Zheng L, Bork P, Kafatos FC. 2002. Immunityrelated genes and gene families in Anopheles gambiae. Science 298:159-65. doi:10.1126/science.1077136

Cowieson NP, Edwards-Gayle CJC, Inoue K, Khunti NS, Doutch J, Williams E, Daniels S, Preece G, Krumpa NA, Sutter JP, Tully AD, Terrill NJ, Rambo RP. 2020. Beamline B21: 
High-throughput small-angle X-ray scattering at Diamond Light Source. J Synchrotron Radiat 27. doi:10.1107/S1600577520009960

Dudchenko O, Batra SS, Omer AD, Nyquist SK, Hoeger M, Durand NC, Shamim MS, Machol I, Lander ES, Aiden AP, Aiden EL. 2017. De novo assembly of the Aedes aegypti genome using Hi-C yields chromosome-length scaffolds. Science (80-) doi:10.1126/science.aal3327

Dzaki N, Ramli KN, Azlan A, Ishak IH, Azzam G. 2017. Evaluation of reference genes at different developmental stages for quantitative real-time PCR in Aedes aegypti. Sci Rep. doi: $10.1038 /$ srep43618

Edgar RC. 2004. MUSCLE: A multiple sequence alignment method with reduced time and space complexity. BMC Bioinformatics. doi:10.1186/1471-2105-5-113

Emsley P, Lohkamp B, Scott WG, Cowtan K. 2010. Features and development of Coot. Acta Crystallogr Sect D Biol Crystallogr. doi:10.1107/S0907444910007493

Ewald SE, Engel A, Lee J, Wang M, Bogyo M, Barton GM. 2011. Nucleic acid recognition by Toll-like receptors is coupled to stepwise processing by cathepsins and asparagine endopeptidase. $J$ Exp Med 208. doi:10.1084/jem.20100682

Ewald SE, Lee BL, Lau L, Wickliffe KE, Shi G-P, Chapman H a, Barton GM. 2008. The ectodomain of Toll-like receptor 9 is cleaved to generate a functional receptor. Nature 456:658-62. doi:10.1038/nature07405

Foldi I, Anthoney N, Harrison N, Gangloff M, Verstak B, Nallasivan MP, AlAhmed S, Zhu B, Phizacklea M, Losada-Perez M, Moreira M, Gay NJ, Hidalgo A. 2017. Three-tier regulation of cell number plasticity by neurotrophins and Tolls in Drosophila. J Cell Biol 216. doi:10.1083/jcb. 201607098

Franke D, Petoukhov M V., Konarev P V., Panjkovich A, Tuukkanen A, Mertens HDT, Kikhney AG, Hajizadeh NR, Franklin JM, Jeffries CM, Svergun DI. 2017. ATSAS 2.8: A comprehensive data analysis suite for small-angle scattering from macromolecular solutions. J Appl Crystallogr. doi:10.1107/S1600576717007786

Gangloff M., Murali A, Xiong J, Arnot CJ, Weber AN, Sandercock AM, Robinson CV, Sarisky R, Holzenburg A, Kao C, Gay NJ. 2008. Structural insight into the mechanism of activation of the toll receptor by the dimeric ligand Spätzle. J Biol Chem 283. doi:10.1074/jbc.M800112200

Gangloff Monique, Murali A, Xiong J, Arnot CJCJ, Weber ANAN, Sandercock AMAM, Robinson CVC V., Sarisky R, Holzenburg A, Kao C, Gay NJNJ. 2008. Structural insight into the mechanism of activation of the toll receptor by the dimeric ligand Sp??tzle. J Biol Chem 283:14629-14635. doi:10.1074/jbc.M800112200

Gay NJ, Gangloff M. 2007. Structure and function of Toll receptors and their ligands. Annu Rev Biochem 76:141-165.

Gay NJ, Gangloff M, Weber AN. 2006. Toll-like receptors as molecular switches. Nat Rev Immunol 6:693-698. doi:nri1916 [pii]10.1038/nri1916

Gay NJJNJ, Symmons MFFMF, Gangloff M, Bryant CEECE. 2014. Assembly and localization of Toll-like receptor signalling complexes. Nat Rev Immunol 14:546-558. doi:10.1038/nri3713

Giraldo-Calderón GI, Emrich SJ, MacCallum RM, Maslen G, Emrich S, Collins F, Dialynas E, Topalis P, Ho N, Gesing S, Madey G, Collins FH, Lawson D, Kersey P, Allen J, Christensen M, Hughes D, Koscielny G, Langridge N, Gallego EL, Megy K, Wilson D, Gelbart B, Emmert D, Russo S, Zhou P, Christophides G, Brockman A, Kirmitzoglou I, MacCallum B, Tiirikka T, Louis K, Dritsou V, Mitraka E, Werner-Washburn M, Baker P, Platero H, Aguilar A, Bogol S, Campbell D, Carmichael R, Cieslak D, Davis G, Konopinski N, Nabrzyski J, Reinking C, Sheehan A, Szakonyi S, Wieck R. 2015. VectorBase: An updated Bioinformatics Resource for invertebrate vectors and other 
organisms related with human diseases. Nucleic Acids Res 43. doi:10.1093/nar/gku1117

Ha SH, Ferrell JE. 2016. Thresholds and ultrasensitivity from negative cooperativity. Science (80- ) 352. doi:10.1126/science.aad5937

Hoffmann A, Funkner A, Neumann P, Juhnke S, Walther M, Schierhorn A, Weininger U, Balbach J, Reuter G, Stubbs MT. 2008. Biophysical characterization of refolded Drosophila spätzle, a cystine knot protein, reveals distinct properties of three isoforms. $J$ Biol Chem. doi:10.1074/jbc.M801815200

Hoffmann JA. 2003. The immune response of Drosophila. Nature. doi:10.1038/nature02021

Inaki M, Shinza-Kameda M, Ismat A, Frasch M, Nose A. 2010. Drosophila Tey represses transcription of the repulsive cue Toll and generates neuromuscular target specificity. Development. doi: $10.1242 /$ dev.046672

Jang IH, Chosa N, Kim SH, Nam HJ, Lemaitre B, Ochiai M, Kambris Z, Brun S, Hashimoto C, Ashida M, Brey PT, Lee WJ. 2006. A Spätzle-processing enzyme required for toll signaling activation in drosophila innate immunity. Dev Cell 10. doi:10.1016/j.devcel.2005.11.013

Kang JY, Lee JO. 2011. Structural biology of the toll-like receptor family. Annu Rev Biochem 80. doi:10.1146/annurev-biochem-052909-141507

Keith FJ, Gay NJ. 1990. The Drosophila membrane receptor Toll can function to promote cellular adhesion. EMBO J 9:4299-4306. doi:10.1002/j.1460-2075.1990.tb07878.x

Kidmose RT, Juhl J, Nissen P, Boesen T, Karlsen JL, Pedersen BP. 2019. Namdinator Automatic molecular dynamics flexible fitting of structural models into cryo-EM and crystallography experimental maps. IUCrJ. doi:10.1107/S2052252519007619

Koshland DE. 1996. The structural basis of negative cooperativity: Receptors and enzymes. Curr Opin Struct Biol 6. doi:10.1016/S0959-440X(96)80004-2

Krantz DE, Zipursky SL. 1990. Drosophila chaoptin, a member of the leucine-rich repeat family, is a photoreceptor cell-specific adhesion molecule. EMBO J9. doi:10.1002/j.14602075.1990.tb08325.x

Laue TM, Shah BD, Ridgeway TM PS. 1992. Computer-aided interpretation of analytical sedimentation data for proteins. Analytical Ultracentrifugation in Biochemistry and Polymer Science. Royal Society of Chemistry, Cambridge, UK.

Leonard JN, Ghirlando R, Askins J, Bell JK, Margulies DH, Davies DR, Segal DM. 2008. The TLR3 signaling complex forms by cooperative receptor dimerization. Proc Natl Acad Sci U S A 105:258-63. doi:10.1073/pnas.0710779105

Levin D, Harari D, Schreiber G. 2011. Stochastic Receptor Expression Determines Cell Fate upon Interferon Treatment. Mol Cell Biol 31. doi:10.1128/mcb.05251-11

Levitzki A, Koshland DE. 1969. Negative cooperativity in regulatory enzymes. Proc Natl Acad Sci U S A 62. doi:10.1073/pnas.62.4.1121

Lewis M, Arnot CJCJ, Beeston H, McCoy A, Ashcroft AEAE, Gay NJNJ, Gangloff M. 2013. Cytokine Spatzle binds to the Drosophila immunoreceptor Toll with a neurotrophin-like specificity and couples receptor activation. Proc Natl Acad Sci U S A 110:20461-6. doi:10.1073/pnas.1317002110

Liu L, Botos I, Wang Y, Leonard JN, Shiloach J, Segal DM, Davies DR. 2008. Structural basis of toll-like receptor 3 signaling with double-stranded RNA. Science 320:379-81. doi:10.1126/science. 1155406

Lum L, Beachy PA. 2004. The hedgehog response network: Sensors, switches, and routers. Science (80- ). doi:10.1126/science.1098020

Luna C, Hoa NT, Zhang J, Kanzok SM, Brown SE, Imler JL, Knudson DL, Zheng L. 2003. Characterization of three Toll-like genes from mosquito Aedes aegypti. Insect Mol Biol 12:67-74. doi:10.1046/j.1365-2583.2003.00388.x

Luo C, Shen B, Manley JL, Zheng L. 2001. Tehao functions in the Toll pathway in Drosophila 
melanogaster: Possible roles in development and innate immunity. Insect Mol Biol 10:457-464. doi:10.1046/j.0962-1075.2001.00284.x

Luplertlop N, Surasombatpattana P, Patramool S, Dumas E, Wasinpiyamongkol L, Saune L, Hamel R, Bernard E, Sereno D, Thomas F, Piquemal D, Yssel H, Briant L, Missé D. 2011. Induction of a Peptide with Activity against a Broad Spectrum of Pathogens in the Aedes aegypti Salivary Gland, following Infection with Dengue Virus. PLoS Pathog 7:e1001252. doi:10.1371/journal.ppat.1001252

Maschalidi S, Hässler S, Blanc F, Sepulveda FE, Tohme M, Chignard M, van Endert P, SiTahar M, Descamps D, Manoury B. 2012. Asparagine Endopeptidase Controls AntiInfluenza Virus Immune Responses through TLR7 Activation. PLoS Pathog. doi:10.1371/journal.ppat.1002841

McIlroy G, Foldi I, Aurikko J, Wentzell JS, Lim MA, Fenton JC, Gay NJ, Hidalgo A. 2013. SI - Toll-6 and Toll-7 function as neurotrophin receptors in the Drosophila melanogaster CNS. Nat Neurosci 16:1248-56. doi:10.1038/nn.3474

Moraga I, Harari D, Schreiber G, Uzé G, Pellegrini S. 2009. Receptor Density Is Key to the Alpha2/Beta Interferon Differential Activities. Mol Cell Biol 29. doi:10.1128/mcb.0180808

Moraga I, Richter D, Wilmes S, Winkelmann H, Jude K, Thomas C, Suhoski MM, Engleman EG, Piehler J, Garcia KC. 2015. Instructive roles for cytokine-receptor binding parameters in determining signaling and functional potency. Sci Signal 8. doi:10.1126/scisignal.aab2677

Nakamoto M, Moy RH, Xu J, Bambina S, Yasunaga A, Shelly SS, Gold B, Cherry S. 2012. Virus Recognition by Toll-7 Activates Antiviral Autophagy in Drosophila. Immunity 36:658-667. doi:10.1016/j.immuni.2012.03.003

Nene V, Wortman JR, Lawson D, Haas B, Kodira C, Tu ZJ, Loftus B, Xi Z, Megy K, Grabherr M, Ren Q, Zdobnov EM, Lobo NF, Campbell KS, Brown SE, Bonaldo MF, Zhu J, Sinkins SP, Hogenkamp DG, Amedeo P, Arensburger P, Atkinson PW, Bidwell S, Biedler J, Birney E, Bruggner R V., Costas J, Coy MR, Crabtree J, Crawford M, DeBruyn B, Decaprio D, Eiglmeier K, Eisenstadt E, El-Dorry H, Gelbart WM, Gomes SL, Hammond M, Hannick LI, Hogan JR, Holmes MH, Jaffe D, Johnston JS, Kennedy RC, Koo H, Kravitz S, Kriventseva E V., Kulp D, LaButti K, Lee E, Li S, Lovin DD, Mao C, Mauceli E, Menck CFMM, Miller JR, Montgomery P, Mori A, Nascimento AL, Naveira HF, Nusbaum C, O'Leary S, Orvis J, Pertea M, Quesneville H, Reidenbach KR, Rogers YHH, Roth CW, Schneider JR, Schatz M, Shumway M, Stanke M, Stinson EO, Tubio JMCC, Vanzee JP, Verjovski-Almeida S, Werner D, White O, Wyder S, Zeng Q, Zhao Q, Zhao Y, Hill CA, Raikhel AS, Soares MB, Knudson DL, Lee NH, Galagan J, Salzberg SL, Paulsen IT, Dimopoulos G, Collins FH, Birren B, Fraser-liggett CM, Severson DW, Leary SO, Orvis J, Pertea M, Quesneville H, Reidenbach KR, Stanke M, Stinson EO, Tubio JMCC, Vanzee JP, Zhao Q, Zhao Y, Hill CA, Raikhel AS, Soares MB, Knudson DL, Lee NH, Galagan J, Salzberg SL, Paulsen IT, Dimopoulos G, Collins FH, Birren B, Fraserliggett CM, Severson DW. 2007. Genome sequence of Aedes aegypti, a major arbovirus vector. Science 316:1718-23. doi:10.1126/science.1138878

Nonaka S, Kawamura K, Hori A, Salim E, Fukushima K, Nakanishi Y, Kuraishi T. 2018. Characterization of Spz5 as a novel ligand for Drosophila Toll-1 receptor. Biochem Biophys Res Commun. doi:10.1016/j.bbrc.2018.10.096

Nose A, Mahajan VB, Goodman CS. 1992. Connectin: A homophilic cell adhesion molecule expressed on a subset of muscles and the motoneurons that innervate them in Drosophila. Cell. doi:10.1016/0092-8674(92)90426-D

Palatini U, Masri RA, Cosme L V., Koren S, Thibaud-Nissen F, Biedler JK, Krsticevic F, Johnston JS, Halbach R, Crawford JE, Antoshechkin I, Failloux AB, Pischedda E, 
Marconcini M, Ghurye J, Rhie A, Sharma A, Karagodin DA, Jenrette J, Gamez S, Miesen P, Masterson P, Caccone A, Sharakhova M V., Tu Z, Papathanos PA, Van Rij RP, Akbari OS, Powell J, Phillippy AM, Bonizzoni M. 2020. Improved reference genome of the arboviral vector Aedes albopictus. Genome Biol. doi:10.1186/s13059-020-02141-w

Park B, Brinkmann MM, Spooner E, Lee CC, Kim YM, Ploegh HL. 2008. Proteolytic cleavage in an endolysosomal compartment is required for activation of Toll-like receptor 9. Nat Immunol 9. doi:10.1038/ni.1669

Parker JS, Mizuguchi K, Gay NJ. 2001. A family of proteins related to Spatzle, the toll receptor ligand, are encoded in the Drosophila genome. Proteins 45:71-80. doi:10.1002/prot.1125 [pii]

Parthier C, Stelter M, Ursel C, Fandrich U, Lilie H, Breithaupt C, Stubbs MT. 2014. Structure of the Toll-Spatzle complex, a molecular hub in Drosophila development and innate immunity. Proc Natl Acad Sci U S A 111:6281-6. doi:10.1073/pnas.1320678111

Pettersen EF, Goddard TD, Huang CC, Couch GS, Greenblatt DM, Meng EC, Ferrin TE. 2004. UCSF Chimera--a visualization system for exploratory research and analysis. J Comput Chem 25:1605-12. doi:10.1002/jcc.20084

Punjani A, Rubinstein JL, Fleet DJ, Brubaker MA. 2017. CryoSPARC: Algorithms for rapid unsupervised cryo-EM structure determination. Nat Methods. doi:10.1038/nmeth.4169

Rambo RP, Tainer JA. 2011. Characterizing flexible and intrinsically unstructured biological macromolecules by SAS using the Porod-Debye law. Biopolymers 95. doi:10.1002/bip.21638

Ramirez JL, Dimopoulos G. 2010. The Toll immune signaling pathway control conserved antidengue defenses across diverse Ae. aegypti strains and against multiple dengue virus serotypes. Dev Comp Immunol 34:625-629. doi:10.1016/j.dci.2010.01.006

Roed NK, Viola CM, Kristensen O, Schluckebier G, Norrman M, Sajid W, Wade JD, Andersen AS, Kristensen C, Ganderton TR, Turkenburg JP, De Meyts P, Brzozowski AM. 2018. Structures of insect Imp-L2 suggest an alternative strategy for regulating the bioavailability of insulin-like hormones. Nat Commun. doi:10.1038/s41467-018-06192-3

Rose D, Zhu X, Kose H, Hoang B, Cho J, Chiba A. 1997. Toll, a muscle cell surface molecule, locally inhibits synaptic initiation of the RP3 motoneuron growth cone in Drosophila. Development.

Rosenthal PB, Rubinstein JL. 2015. Validating maps from single particle electron cryomicroscopy. Curr Opin Struct Biol. doi:10.1016/j.sbi.2015.07.002

Schuck P. 2000. Size-distribution analysis of macromolecules by sedimentation velocity ultracentrifugation and Lamm equation modeling. Biophys $J$. doi:10.1016/S00063495(00)76713-0

Sepulveda FE, Maschalidi S, Colisson R, Heslop L, Ghirelli C, Sakka E, Lennon-Duménil AM, Amigorena S, Cabanie L, Manoury B. 2009. Critical Role for Asparagine Endopeptidase in Endocytic Toll-like Receptor Signaling in Dendritic Cells. Immunity. doi:10.1016/j.immuni.2009.09.013

Shelly S, Lukinova N, Bambina S, Berman A, Cherry S. 2009. Autophagy Is an Essential Component of Drosophila Immunity against Vesicular Stomatitis Virus. Immunity 30:588-598. doi:10.1016/j.immuni.2009.02.009

Shin SW, Bian G, Raikhel AS. 2006. A toll receptor and a cytokine, Toll5A and Spz1C, are involved in toll antifungal immune signaling in the mosquito Aedes aegypti. $J$ Biol Chem 281:39388-39395. doi:10.1074/jbc.M608912200

Svergun DI. 1992. Determination of the regularization parameter in indirect-transform methods using perceptual criteria. J Appl Crystallogr. doi:10.1107/S0021889892001663

Tanji H, Ohto U, Shibata T, Miyake K, Shimizu T. 2013. Structural reorganization of the Tolllike receptor 8 dimer induced by agonistic ligands. Sci (Washington, DC, United States) 
339:1426-1429. doi:10.1126/science.1229159

Tanji T, Hu X, Weber ANR, Ip YT. 2007. Toll and IMD Pathways Synergistically Activate an Innate Immune Response in Drosophila melanogaster. Mol Cell Biol 27. doi:10.1128/mcb.01814-06

Tegunov D, Cramer P. 2019. Real-time cryo-electron microscopy data preprocessing with Warp. Nat Methods. doi:10.1038/s41592-019-0580-y

Terwilliger TC, Ludtke SJ, Read RJ, Adams PD, Afonine P V. 2020. Improvement of cryo-EM maps by density modification. Nat Methods. doi:10.1038/s41592-020-0914-9

Terwilliger TC, Ludtke SJ, Read RJ, Adams PD, Afonine P V. 2019. Improvement of cryo-EM maps by density modification. bioRxiv. doi:10.1101/845032

Uff S, Clemetson JM, Harrison T, Clemetson KJ, Emsley J. 2002. Crystal structure of the platelet glycoprotein Ib $\alpha$ N-terminal domain reveals an unmasking mechanism for receptor activation. $J$ Biol Chem 277. doi:10.1074/jbc.M205271200

Wang JM, Cheng Y, Shi ZK, Li XF, Xing LS, Jiang H, Wen D, Deng YQ, Zheng AH, Qin CF, Zou Z. 2019. Aedes aegypti HPX8C modulates immune responses against viral infection. PLoS Negl Trop Dis. doi:10.1371/journal.pntd.0007287

Wang L, Gilbert RJC, Atilano ML, Filipe SR, Gay NJ, Ligoxygakis P. 2008. Peptidoglycan recognition protein-SD provides versatility of receptor formation in Drosophila immunity. Proc Natl Acad Sci U S A 105. doi:10.1073/pnas.0710092105

Waterhouse AM, Procter JB, Martin DMA, Clamp M, Barton GJ. 2009. Jalview Version 2-A multiple sequence alignment editor and analysis workbench. Bioinformatics. doi:10.1093/bioinformatics/btp033

Waterhouse RM, Kriventseva E V, Meister S, Xi Z, Alvarez KS, Bartholomay LC, BarillasMury C, Bian G, Blandin S, Christensen BM, Dong Y, Jiang H, Kanost MR, Koutsos AC, Levashina EA, Li J, Ligoxygakis P, Maccallum RM, Mayhew GF, Mendes A, Michel K, Osta MA, Paskewitz S, Shin SW, Vlachou D, Wang L, Wei W, Zheng L, Zou Z, Severson DW, Raikhel AS, Kafatos FC, Dimopoulos G, Zdobnov EM, Christophides GK. 2007. Evolutionary dynamics of immune-related genes and pathways in disease-vector mosquitoes. Science (80- ) 316:1738-43. doi:10.1126/science.1139862

Webb B, Sali A. 2014. Comparative Protein Structure Modeling Using MODELLER. Curr Protoc Bioinformatics 47:5.6.1-5.6.32. doi:10.1002/0471250953.bi0506s47

Weber ANR, Moncrieffe MC, Gangloff M, Imler JL, Gay NJ. 2005. Ligand-receptor and receptor-receptor interactions act in concert to activate signaling in the Drosophila toll pathway. J Biol Chem 280:22793-22799.

Weber ANRR, Tauszig-Delamasure S, Hoffmann JA, Lelièvre E, Gascan H, Ray KP, Morse MA, Imler J-LL, Gay NJ. 2003. Binding of the Drosophila cytokine Spätzle to Toll is direct and establishes signaling. Nat Immunol 4:794-800. doi:10.1038/ni955

Xi Z, Ramirez JL, Dimopoulos G, Barillas-Mury C, Conklin B, Feinstone WH. 2008. The Aedes aegypti toll pathway controls dengue virus infection. PLoS Pathog 4:e1000098. doi:10.1371/journal.ppat.1000098

Xiao X, Liu Y, Zhang X, Wang J, Li Z, Pang X, Wang P, Cheng G. 2014. Complement-Related Proteins Control the Flavivirus Infection of Aedes aegypti by Inducing Antimicrobial Peptides. PLoS Pathog. doi:10.1371/journal.ppat.1004027 